128 ANL-7476 $12 / 23168$
120

79

FAST REACTOR

575

FAST REACTOR SAFEANL-7476

Argonne Mational Laboratoru

THE EBR-II FEEDBACK FUNCTION

by

R. W. Hyndman and

R. B. Nicholson 


\section{DISCLAIMER}

This report was prepared as an account of work sponsored by an agency of the United States Government. Neither the United States Government nor any agency Thereof, nor any of their employees, makes any warranty, express or implied, or assumes any legal liability or responsibility for the accuracy, completeness, or usefulness of any information, apparatus, product, or process disclosed, or represents that its use would not infringe privately owned rights. Reference herein to any specific commercial product, process, or service by trade name, trademark, manufacturer, or otherwise does not necessarily constitute or imply its endorsement, recommendation, or favoring by the United States Government or any agency thereof. The views and opinions of authors expressed herein do not necessarily state or reflect those of the United States Government or any agency thereof. 


\section{DISCLAIMER}

Portions of this document may be illegible in electronic image products. Images are produced from the best available original document. 
The facilities of Argonne National Laboratory are owned by the United States Government. Under the terms of a contract (W-31-109-Eng-38) between the U. S. Atomic Energy Commission, Argonne Universities Association and The University of Chicago, the University employs the staff and operates the Laboratory in accordance with policies and programs formulated, approved and reviewed by the Association.

\section{MEMBERS OF ARGONNE UNIVERSITIES ASSOCIATION}

The University of Arizona

Carnegie-Mellon University

Case Western Reserve University

The University of Chicago

University of Cincinnati

Illinois Institute of Technology

University of Illinois

Indiana University

Iowa State University

The University of Iowa
Kansas State University The University of Kansas Loyola University Marquette University Michigan State University The University of Michigan University of Minnesota University of Missouri Northwestern University University of Notre Dame
The Ohio State University Ohio University

The Pennsylvania State University Purdue University Saint Louis University Southern Illinois University University of Texas Washington University Wayne State University The University of Wisconsin

\section{LEGAL NOTICE}

This report was prepared as an account of Government sponsored work. Neither the United States, nor the Commission, nor any person acting on behalf of the Commission:

A. Makes any warranty or representation, expressed or implied, with respect to the accuracy, completeness, or usefulness of the information contained in this report, or that the use of any information, apparatus, method, or process disclosed in this report may not infringe privately owned rights; or

B. Assumes any liabilities with respect to the use of, or for damages resulting from the use of any information, apparatus, method, or process disclosed in this report.

As used in the above, "person acting on behalf of the Commission" includes any employee or contractor of the Commission, or employee of such contractor, to the extent that such employee or contractor of the Commission, or employee of such contractor prepares, disseminates, or provides access to, any information pursuant to his employment or contract with the Commission, or his employment with such contractor.

Printed in the United States of America Available from

Clearinghouse for Federal Scientific and Technical Information National Bureau of Standards, U. S. Department of Commerce Springfield, Virginia 22151

Price: Printed Copy $\$ 3.00$; Microfiche $\$ 0.65$ 


\section{ARGONNE NATIONAL LABORATORY 9700 South Cass Avenue Argonne, Illinois 60439}

THE EBR-II FEEDBACK FUNCTION

by

R. W. Hyndman and

R. B. Nicholson

Idaho Division

This report was prepared as an account of Government sponsored work. Neither the United States,

A the accuracy, complate or usefuiness of the information contalned in this report, or that the use of any information, apparatus, method, or process disclosed in this report may not infringe privately owned rights; or

B. Assumes any liabilities with respect to the use of, or for damages resulting from the use of any information, apparatus, method, or process disclosed in this report.

As used in the sbove. "person acting on behalf of the Commission" includes any employee or contractor of the Commission, or employee of such contractor, to the extent that tsuch employee or contractor of the Commission, or employee of such contractor prepares, dlsseminates, or provides access to, any Information pursuant

with the ch. 
HS THIS PAGE WAS INTENTIONALLY LEFT BLANK 
TABLE OF CONTENTS

Page

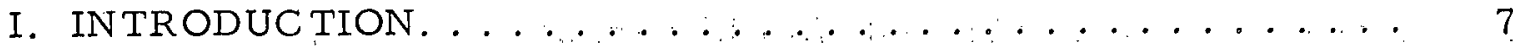

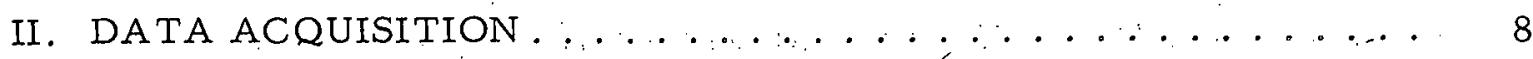

III. ROD-OSCILLATOR EXPERIMENTS. ............ 11

IV. ROD-DROP EXPERIMENTS ............................ 19

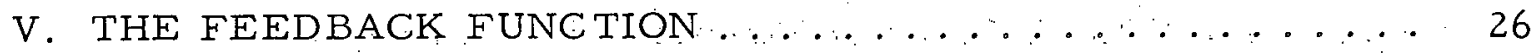

A. Feedback Function from Oscillator Data ......... 26

B. Feedback Function from Rod-drop Experiments ...... 32

C. Feedback Function by Compromise between Oscillator and

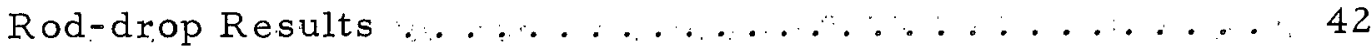

D. Further Discussion and Summary.............. 45

VI. RECOMMENDATIONS FOR FUTURE EXPERIMENTS $\ldots . \quad \therefore 47$

APPENDIX A. Heat-transfer Calculations ............ 49

APPENDIX B. Delayed-neutron Constants ............ 55

ACKNOWLEDGMENTS . . . . . . . . . . . . . . . 56

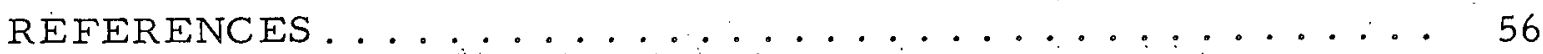




\section{- LIST OF FIGURES}

No.

Title

Page

1. Data-acquisition Equipment, Block Diagram......... 9

2. Amplitude and Phase Error of Measured Zero-power Trans-

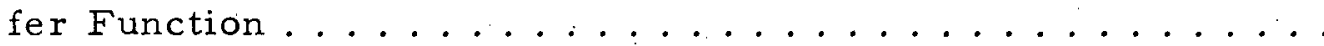

3. Measured and Calculated Values of EBR-II Zero-power

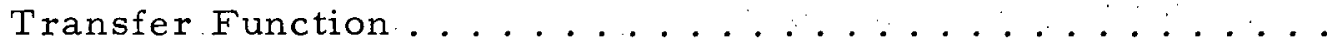

4. Amplitude of EBR-II Transfer Function with Control Rods Banked at 11 in.

5. Phase Lag of EBR-II Transfer Function with Control Rods Banked at 11 in.

6. Amplitude of EBR-II Transfer Function with Control Rods Banked at 12.75 in.

7. Phase Lag of EBR-II Transfer Function with Control Rods Banked at 12.75 in

8. Comparison of EBR-II 22.5-MW and Zero-power Transfer

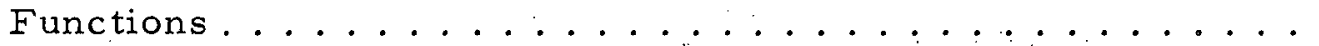

9. Reactivity Calibration of Stainless Steel Rod at 1 1-in.

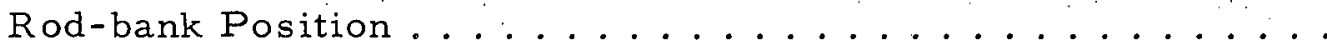

10. Reactivity Calibration of Stainless Steel Rods at 13-in.

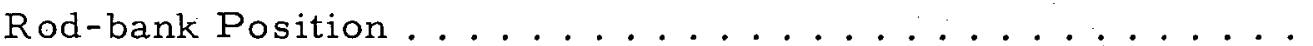

11. Feedback Plot for Rod-drop Experiment for Run $26 \mathrm{~B}$ at $500 \mathrm{~kW}$ with Rod Banked at 11 in.

12. Feedback Plot for Rod-drop Experiment for Run $26 \mathrm{~A}$ at $500 \mathrm{~kW}$

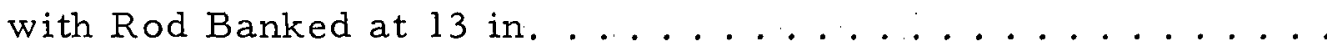

13. Feedback and Power Plots for Rod-drop Experiment for Run $26 \mathrm{~B}$ at $22.5 \mathrm{MWt} \ldots \ldots \ldots \ldots$

14. Feedback and Power Plots for Rod-drop Experiment for Run $26 \mathrm{~B}$ at $30.0 \mathrm{MWt}$

15. Feedback and Power Plots for Rod-drop Experiment for Run $26 \mathrm{~B}$ at $41.4 \mathrm{MWt} \ldots \ldots \ldots \ldots$ 
LIST OF FIGURES

No.

Title

Page

16. Feedback and Power Plots for Rod-drop Experiment for Run 26A at $25.0 \mathrm{MWt} \ldots \ldots \ldots \ldots$

17. Feedback and Power Plots for Rod-drop Experiment for Run 26A at $35.0 \mathrm{MWt} \ldots \ldots \ldots \ldots$

18. Feedback and Power Plots for Rod-drop Experiment for Run 26A at $45.0 \mathrm{MWt} \ldots \ldots \ldots \ldots \ldots$

19. Feedback Plot for Rod-drop Experiment for Run $26 \mathrm{~B}$ at 41.4 MWt with Three Rod Drops Used for Average........

20. Nyquist Plot of Oscillator Feedback Function for Run 26B at $22.5 \mathrm{MWt} \ldots \ldots \ldots \ldots \ldots$

21. Nyquist Plot of Oscillator Feedback Function for Run 26B at

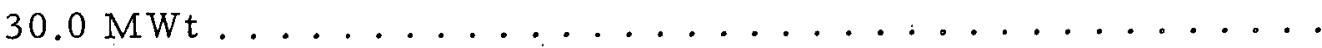

22. Nyquist Plot of Oscillator Feedback Function for Run $26 \mathrm{~B}$ at

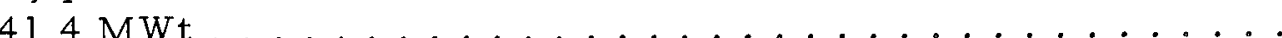

23. Uncorrected Feedback and Model for Run 26B at $30.0 \mathrm{MWt}$. . 34

24. Corrected Feedback and Model for Run $26 \mathrm{~B}$ at $22.5 \mathrm{MWt}$. . . $36^{\circ}$

25. Corrected Feedback and Model for Run 26A at 25.0 MWt. . . 37

26. Corrected Feedback and Model for Run $26 \mathrm{~B}$ at 22.5 MWt,

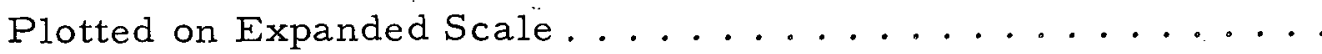

27. Corrected Feedback and Model for Run 26A at 25.0 MWt,

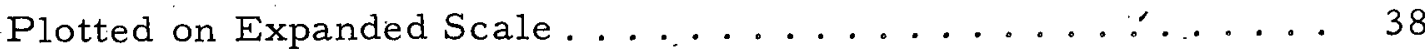

28. Corrected Feedback and Model for Run 26B at $30.0 \mathrm{MWt} \ldots \ldots 38$

29. Corrected Feedback and Model for Run 26A àt $35.0 \mathrm{MWt}$. . . 39

30. Corrected Feedback and Model for Run $26 \mathrm{~B}$ at $41.4 \mathrm{MWt} \ldots .40$

31. Corrected Feedback and Model for Run 26A at $45.0 \mathrm{MWt}$.... 41

32. Nyquist Plot of Oscillator Feedback Function for Run $26 \mathrm{~B}$ at $22.5 \mathrm{MWt}$, Corrected for Oscillator-rod Bowing ........ 


\section{LIST OF FIGURES}

No.

Title

$\underline{\text { Page }}$

33. ARGUS-calculated Temperatures for Row 1.......... 50

34. ARGUS-calculated Temperatures for Row $4 \ldots \ldots 1$

35. ARGUS-calculated Temperatures for Row $6 \ldots \ldots 2$

36. ARGUS-calculated Temperatures for Row 6-7 Interface..... 53

37. ARGUS-calculated Temperatures for Row 8-9 Interface . . . 53 


\title{
THE EBR-II FEEDBACK FUNCTION
}

\section{by}

\author{
R. W. Hyndman and \\ R. B. Nicholson
}

\section{INTRODUC TION}

Considerable effort has been made to assess the system stability of Experimental Breeder Reactor No. 2 (EBR-II), because of both the general need to gain information on fast-reactor systems, and the particular need to maintain safe operation of EBR-II, which plays a crucial role as. an irradiation facility in the Liquid Metal Fast Breeder Reactor. (LMFBR) Program.: EBR-II is a sodium-cooled, metal-alloy-fueled breeder reactor, whose design power level is $62.5 \mathrm{MWt}$. At the time of this report, it was being operated at the initial design level of $45 \mathrm{MWt}$.

The core loadings of EBR-II had been gradually modified over the previous two years to accommodate up to 24 experimental subassemblies-most of which contained oxide or carbide fuels with a lesser fissionable content per subassembly: than the EBR-II driver fuel. The core had initially been surrounded by depleted uranium, but for reasons. connected with the irradiation program, stainless steel had been substituted in the axial blankets and the inner two rows of the radial blanket. These changes were accompanied by a lessening of the negative value of the reactor's power coefficient, and this emphasized the need to study the reactor's feedback function.

This report is the result of an attempt to deduce as much information as possible on the EBR-II feedback function in Run 26 from a series of oscillator and rod-drop experiments performed in October and November 1967. The task is a formidable one because the feedback is weak and there are deficiencies in the experimental equipment, so that significant errors may be introduced. Some suggested improvements are presented in Section VI. It has been necessary to apply to the data some corrections that cannot be verified with full confidence. They are suggested by deviations of the data from what one would expect based upon knowledge of the design of the reactor and its nuclear and heat-transfer characteristics. But with this qualification, we feel that much has been learned from these experiments about the Run 26 feedback function.

At power levels above $30 \mathrm{MWt}$, the oscillator can be operated only over the frequency range 0.1 to $8.8 \mathrm{~Hz}$. At lower frequencies, the oscillator rod rubs on the guide tube. This frequency limitation prevents the 
extraction of information on the low-frequency components from oscillator tests. The high-frequency limitation forces one to normalize to the expected feedback at high frequency. The further factor that there are apparently frequency-dependent bowing effects in the oscillator rod suggests that the rod reactivity amplitude may be frequency-dependent. All these limitations and uncertainties must be considered when analyzing the data for feedback.

In the rod-drop tests, the main limitation is the time required to drop the rod out of the core $(0.28 \mathrm{sec})$. Feedback is expected to begin while the rod is dropping. One therefore cannot calibrate the rod accurately at power during the drop, and a separate calibration must be provided. This has been done by rod-drop experiments at low power (500 kW) where feedback is negligible. From the results of the feedback analysis, however, there is strong evidence that the rod changes worth slightly (perhaps $4 \%$ ) between $500 \mathrm{~kW}$ and $45 \mathrm{MW}$. The data must be corrected for this effect, and the magnitude of the correction is uncertain. Finally, there is a relatively high noise level in the data; this noise level has been partially averaged out by using a high sampling rate and averaging three identical rod drops.

We have stressed the difficulties because the reader should be aware of them to properly evaluate the significance of the results, and because it should be possible to eliminate them in future experiments if one is willing to devote a moderate effort and expense to improvements in the experimental equipment. Nevertheless, we still feel that our results, especially those from the rod-drop experiments, give significant information about the EBR-II Run 26 feedback function.

\section{DATA ACQUISITION}

Figure $l$ is a block diagram of the data-acquisition equipment used for the rod-drop and rod-oscillator experiments at EBR-II.

The power-measuring detector, a General Electric Model NA09 compensated ion chamber, operates without the compensating voltage. The preamplifier $(\mathrm{OA}-1)$ is a solid-state Nexus FET-2 operational amplifier used as a current-to-voltage converter. This unit has the 3-dB point at $500 \mathrm{~Hz}$ with an attenuation of $20 \mathrm{~dB}$ per decade. The amplifiers OA-3 through OA-5 are Nexus operational amplifiers with variable gain from 0.01 to 1000 and the same response characteristics as OA-1. The attenuators 1A-1 through $1 \mathrm{~A}-3$ are $10-t u r n$ potentiometers for adjusting the maximum input to a level acceptable to the analog-to-digital converter. 


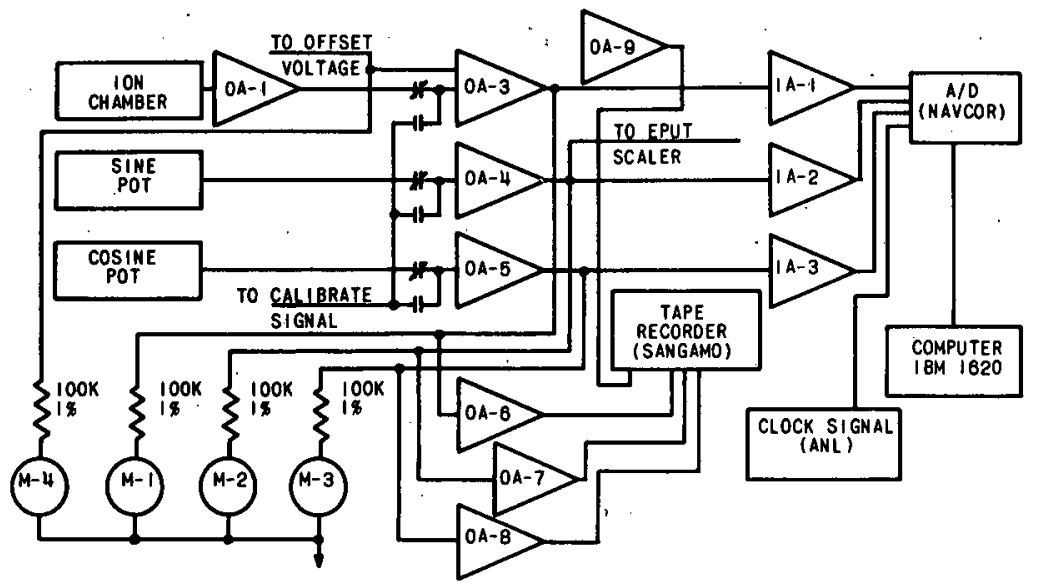

ID-103-J5930

Fig. 1. Data-acquisition Equipment, Block Diagram.

The ion chamber, ion-chamber preamplifier, oscillator drives, sine-cosine potentiometers, and rod-position indicators are located in the reactor building proper. The signals are transmitted over the normal cabling system to the data-acquisition room, a distance of about $300 \mathrm{ft}$. The data-acquisition room contains the signal-conditioning amplifiers, the analog tape recorder, and the control components for conducting the experiments. The data are then transmitted to the computer room, a distance of about 500.ft. The entire system from the preamplifiers to the termination points on the analog-to-digital converter is battery operated with a single-source ground. This method is used to improve the signal-. to-noise ratio to an acceptable level for the analysis routines. Once the tests are started, the signals are continually present at the IBM-1620 computer.

The analog-to-digital converter, shown in Fig. 1 as an A/D NAVCOR, is a field modification to the IBM-1620 computer. The NAVCOR consists of a manually programmed patch-panel selection of one to six channels of analog input signals which can be digitized under control of the computer and an external clock signal. The channels are scanned and digitized in any desired sequence. The digital representation of the signal is transmitted to the computer, with a maximum skew of $160 \mu \mathrm{sec}$ between channels. After one to six channels of data have been transmitted to the computer, the analog-to-digital converter is disconnected and the computer program is in full control of the data for any computations to be done. Since the external clock also affects the analog-to-digital converter, the computer must reconnect to the analog-to-digital converter before the next clock time. Thus, the amount of computation governs the maximum clock rate.

The rod-drop-data experiments have three input signals to the analog-to-digital converter: (a) ion chamber (output of OA-3), (b) rod position (output of $\mathrm{OA}-4$ ), and (c) initiate (output of OA-5). 
The rod position is a 0 - to 10 -volt signal taken from a potentiometer connected to the special stainless steel control rod. The control-rod scram and drive mechanisms are the standard ones used for all the EBR-II control rods. The special control rod has the normal fuel pins replaced by stainless steel pins, thus reducing its worth to approximately $10 \%$ of that of the fueled rods.

The initiate signal is a -5 to +5 -volt signal which initiates the roddrop experiment. The actual rod scram occurs at a preselected time after the initial signal. The delay is usually set at $l \mathrm{sec}$. The initiate signal is interrogated by the computer at each clock time to determine its polarity. If the signal is negative, the data are discarded. At the receipt of the first positive signal, the rod position and the ion-chamber signal are stored for each clock signal until the preselected number of points have been stored. The computer then transfers the stored data to magnetic tape for future data reduction.

The rod-oscillator experiments require: (a) ion-chamber signal (OA-3 output), (b) sine potentiometer (OA-4 output), and (c) cosine potentiometer (OA-5 output).

The sine and cosine voltage come from potentiometers connected directly to the oscillator drive mechanism. The analog-to-digital converter performs the same function as described for the rod-drop experiment and the computer computes a value proportional to the Fourier coefficient as shown:

$$
I m G_{m}=\frac{K_{0}}{N} \sum_{i=1}^{N} E_{i} \sin \left(\omega t_{i}\right)
$$

and

$$
\operatorname{ReG}_{\mathrm{m}}=\frac{\mathrm{K}_{1}}{\mathrm{~N}} \sum_{i=1}^{\mathrm{N}} \mathrm{E}_{\mathrm{i}} \cos \left(\omega \mathrm{t}_{\mathrm{i}}\right),
$$

where

$$
\begin{aligned}
N & =\text { number of sample points, } \\
E & =\text { sampled ion-chamber output, } \\
\mathrm{K}_{0}, \mathrm{~K}_{1} & =\text { gain scaling constants }
\end{aligned}
$$

and

$$
\mathrm{G}_{\mathrm{m}}=\text { measured transfer function. }
$$


The gain of each channel is measured by injecting a known voltage. This known voltage, $\mathrm{E}_{\mathrm{c}}$, is then entered at the computer, and the calibration or gain constant for each channel is calculated as

$$
\operatorname{Gain}_{i}=\frac{1}{2000 E_{c}} \sum_{i=1}^{2000} E_{c_{i}}^{\prime}
$$

where

$$
\mathrm{E}_{\mathrm{C}_{i}}^{\prime}=\text { the value of voltage from the analog-to-digital converter. }
$$

\section{ROD-OSCILLATOR EXPERIMENTS}

The rod-oscillator experiments during Run 26 were conducted with the Mark-II oscillator drive assembly. This unit is a rotary oscillator with a frequency range of $0.001-8.8 \mathrm{~Hz}$. The section of the oscillator through the core is a stainless steel right circular cylinder. This cylinder has two stainless steel tubes attached to the inner wall, located $180^{\circ}$ apart. One tube is filled with boron carbide, the other with aluminum oxide. The aluminum oxide-filled tube has a gas plenum to increase the lifetime of the oscillator. The entire assembly is mounted in a standard control-rod thimble. The drive unit consists of the necessary drive motor, clutches, electrical signaling equipment for indicating the sine and cosine of the shaft position, etc. This unit is mounted on the small rotating plug in place of the standard control-rod drive mechanism.

The data acquisition for the oscillator is described in Section II. The oscillator was checked out by measuring the transfer function of the reactor at zero power, since this can be predicted by other means. The measurement indicated a problem in the measurement and detection systems that could not be accounted for by the normal system checkout and calibration.

Correction factors were then applied to force the error between the calculated and measured zero-power data to be pseudorandom. These correction factors were applied to compensate for system lags and attenuations due to the detection system. Using this form of error correction, the final form was

$$
A c=A m\left[1+\left(\frac{f}{f o_{1}}\right)^{2}\right]^{1 / 2}
$$

and

$$
\phi c=\phi m+\arctan \left(f / f o_{2}\right)
$$


where

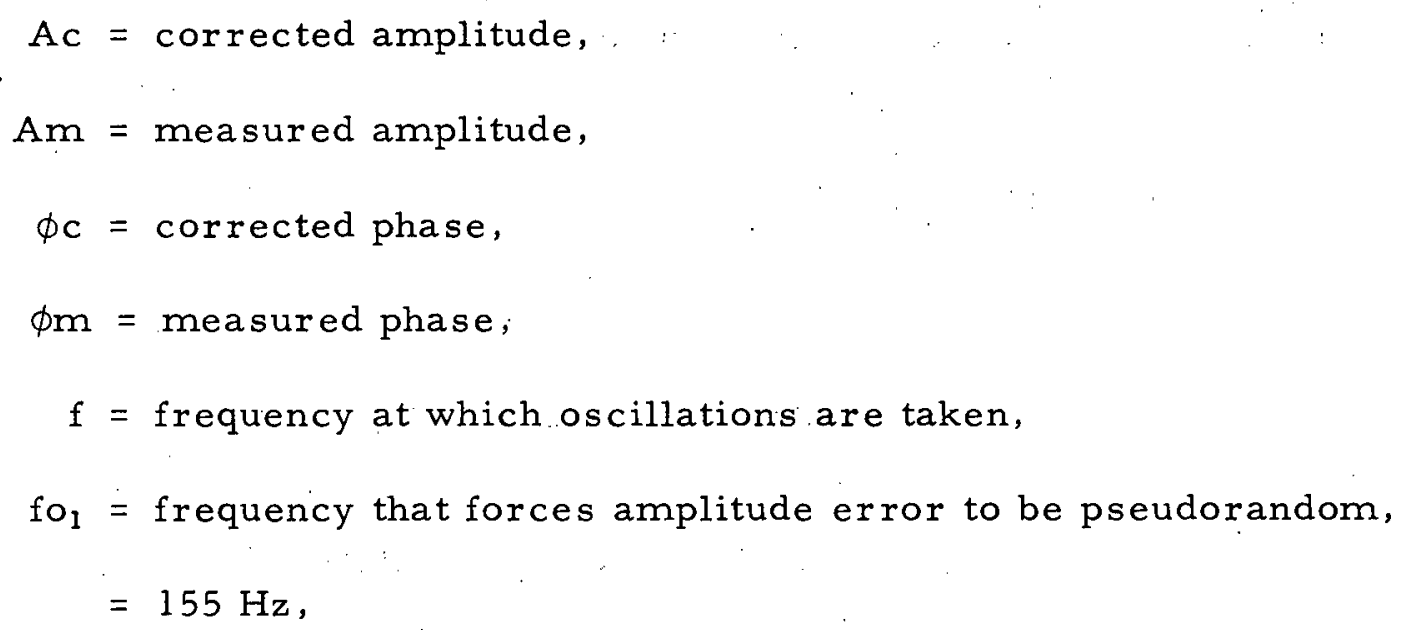

and

$$
\begin{aligned}
\mathrm{fo}_{2} & =\text { frequency that forces phase error to be pseudorandom, } \\
& =65.1 \mathrm{~Hz} .
\end{aligned}
$$

Figure 2 shows the error in the zero-power data after correction; Fig. 3 shows a typical set of zero-power data.

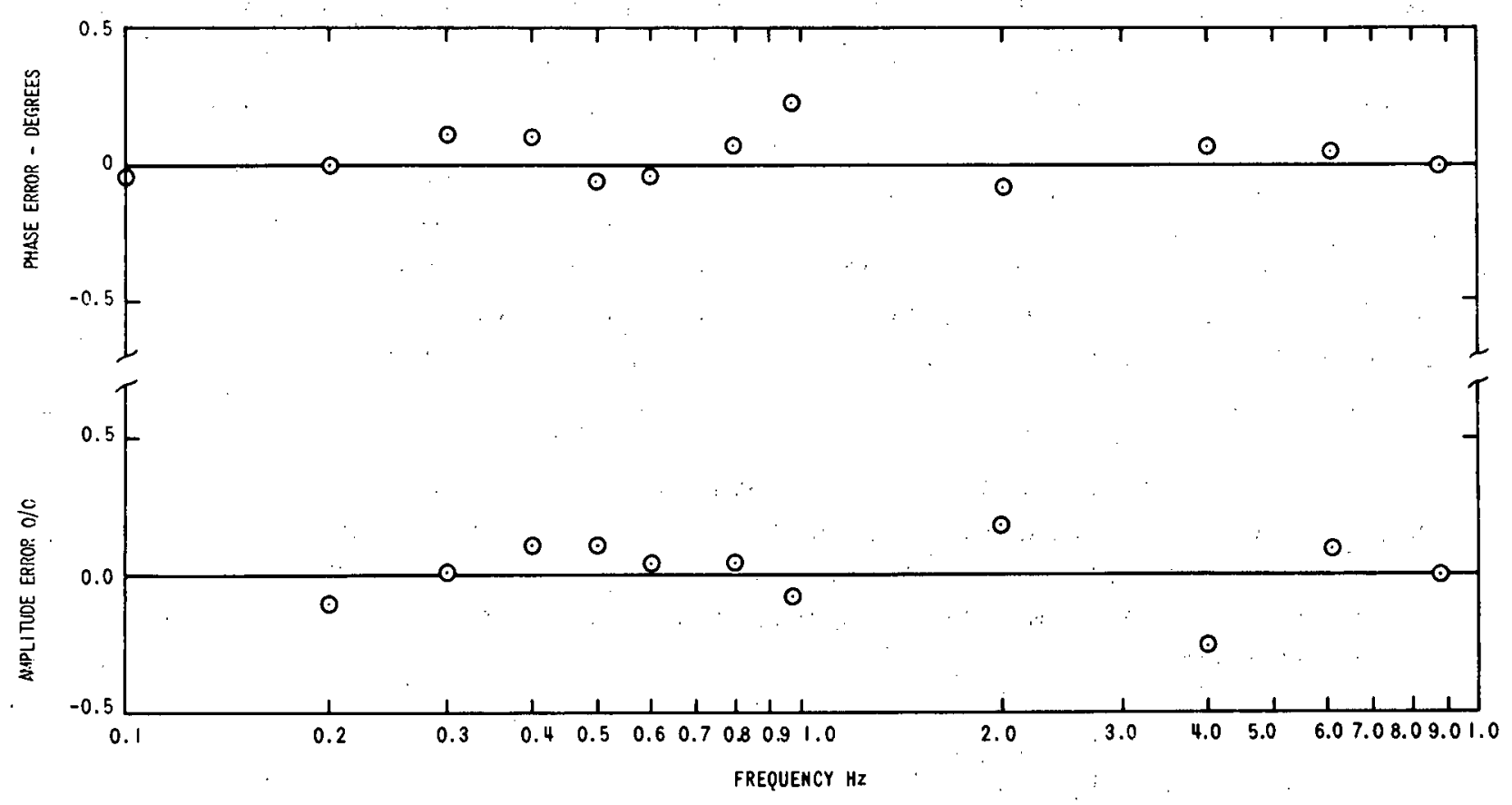

ID-103-K5111

Fig. 2. Amplitude and Phase Error of Measured Zero-power Transfer Function (10/27/67 data) 


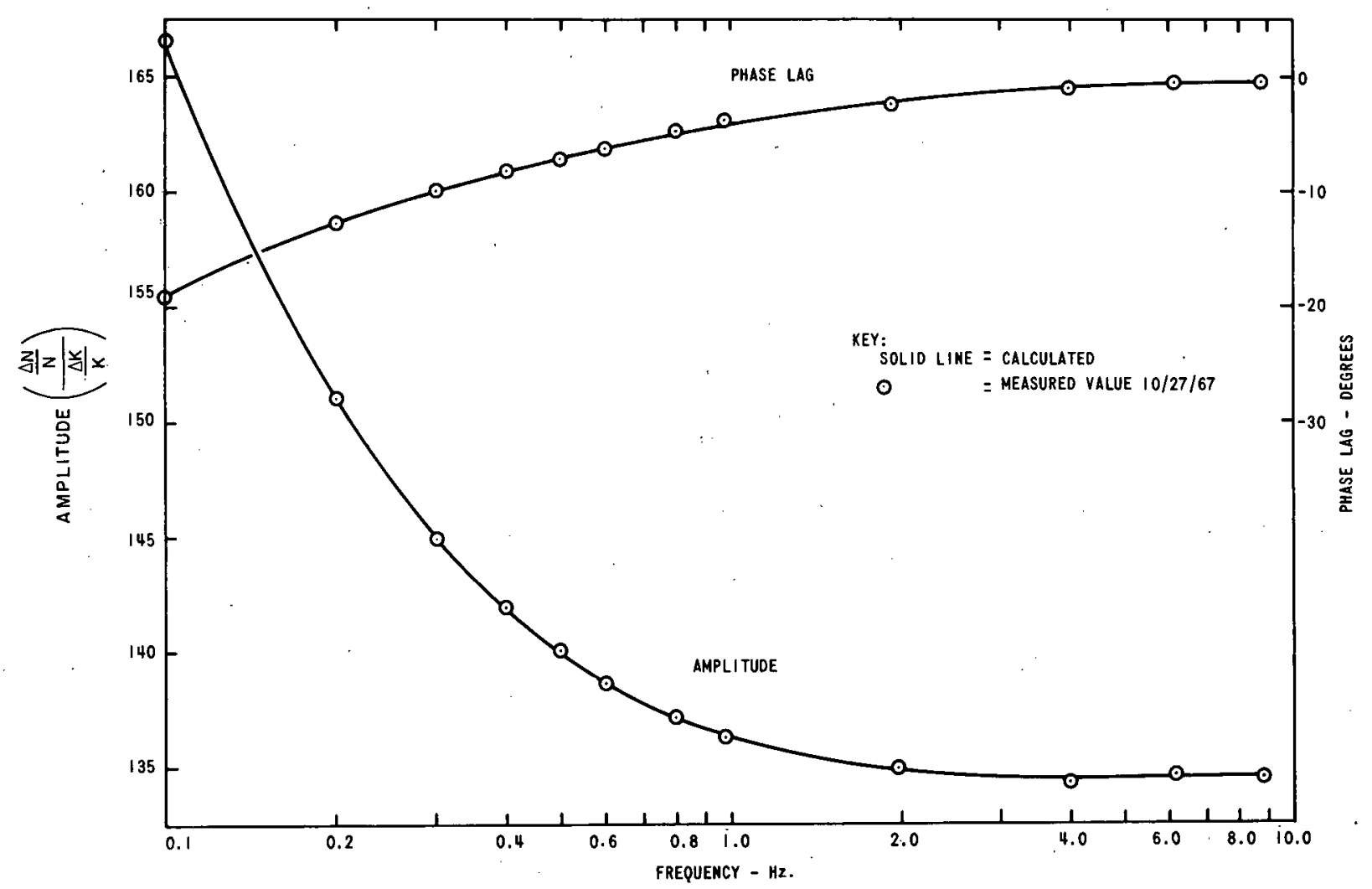

ID -103-K5112 Rev. 1

Fig. 3. Measured and Calculated Values of EBR-II Zero-power Transfer Function

The corrections required to randomize the errors at zero power are also applied to the measured transfer function at higher power levels. The corrected data are presented in Figs. 4-8 for the experiments conducted in Run $26 \mathrm{~B}$ at $22.5,30$, and $41.4 \mathrm{MW}$ at two different rod-bank positions. The data are presented on a Bode plot of amplitude and phase versus frequency and are compared with the zero-power transfer function. The curves indicate that the transfer function at power is exceedingly close to the zeropower transfer function. For this reason, high accuracy is required to determine the feedback. The feedback function, $\mathrm{H}(\mathrm{i} \omega)$, is derived from the power and zero-power curves by subtracting reciprocals. Thus,

$$
H(i \omega)=\frac{1}{G(i \omega)}-\frac{1}{G_{0}(i \omega)}
$$

where $G$ is the transfer function at power, and $G_{0}$ is the zero-power transfer function. The results of this feedback analysis are presented in Section V. 


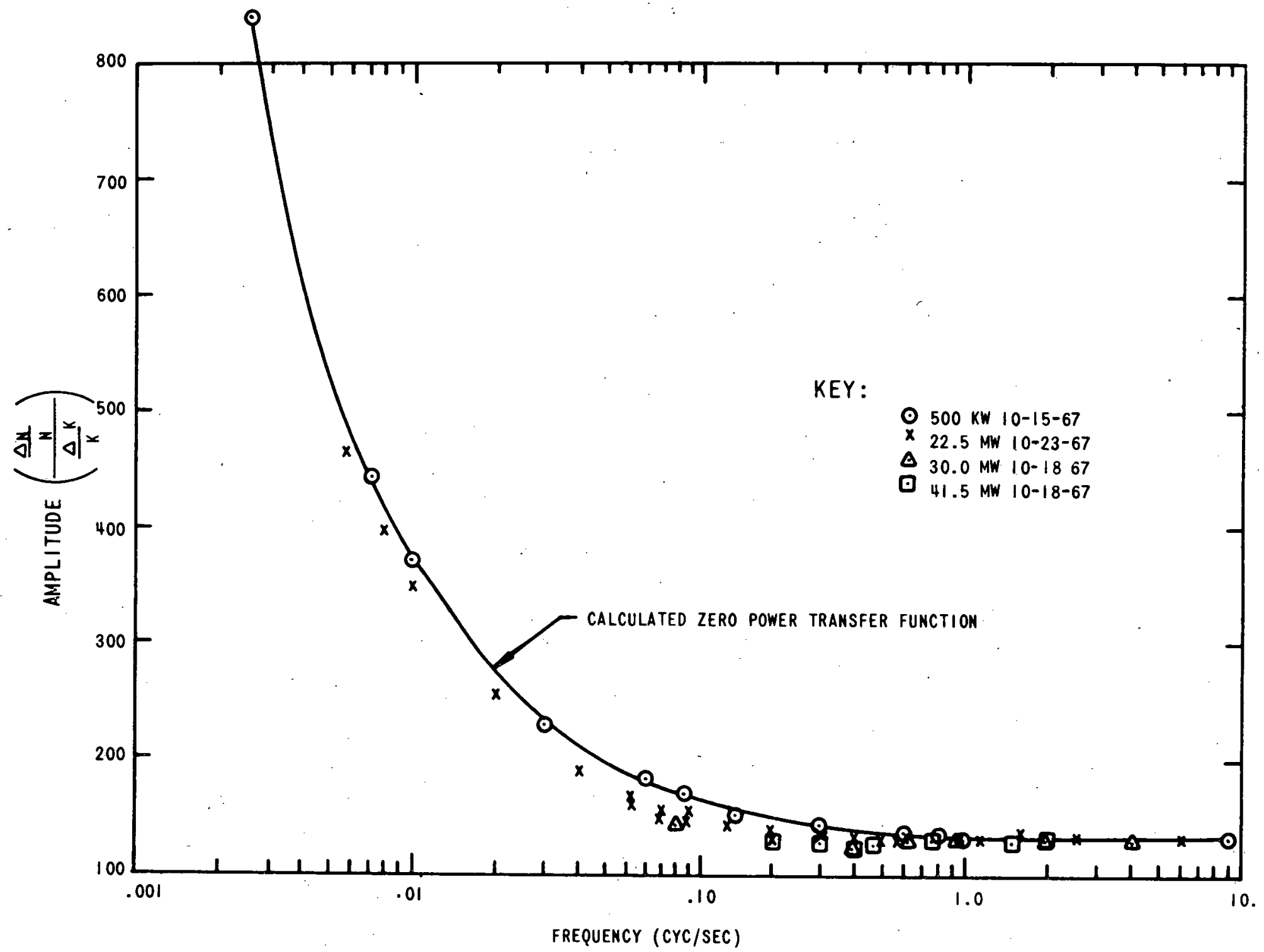

DD-103-K5113

Fig. 4. Amplitude of EBR-II Transfer Function with Control Rods Banked at 11. in. 


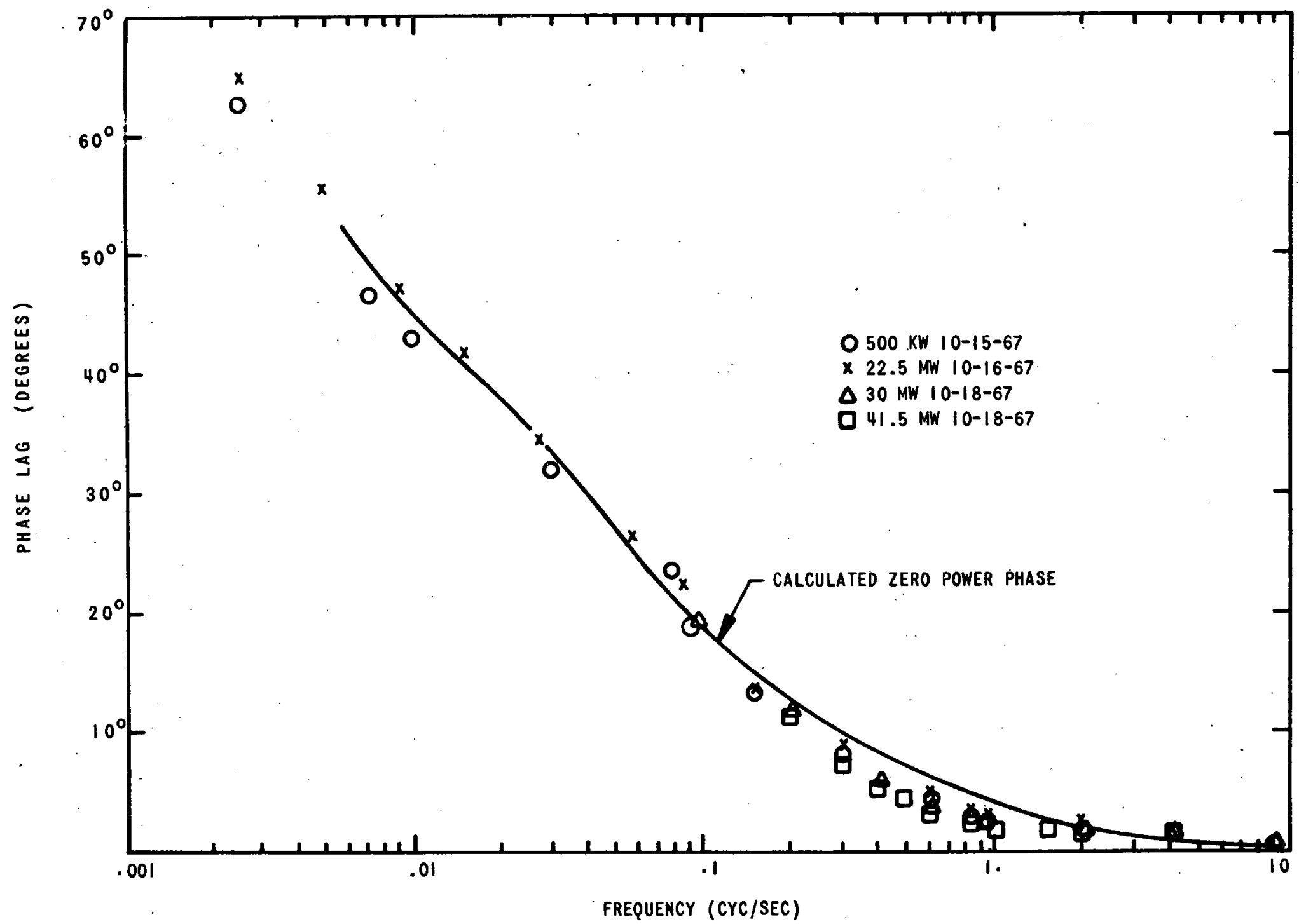

ID-103-K5114 Rev. 1

Fig. 5. Phase Lag of EBR-II Transfer Function with Control Rods Banked at 11 in. 


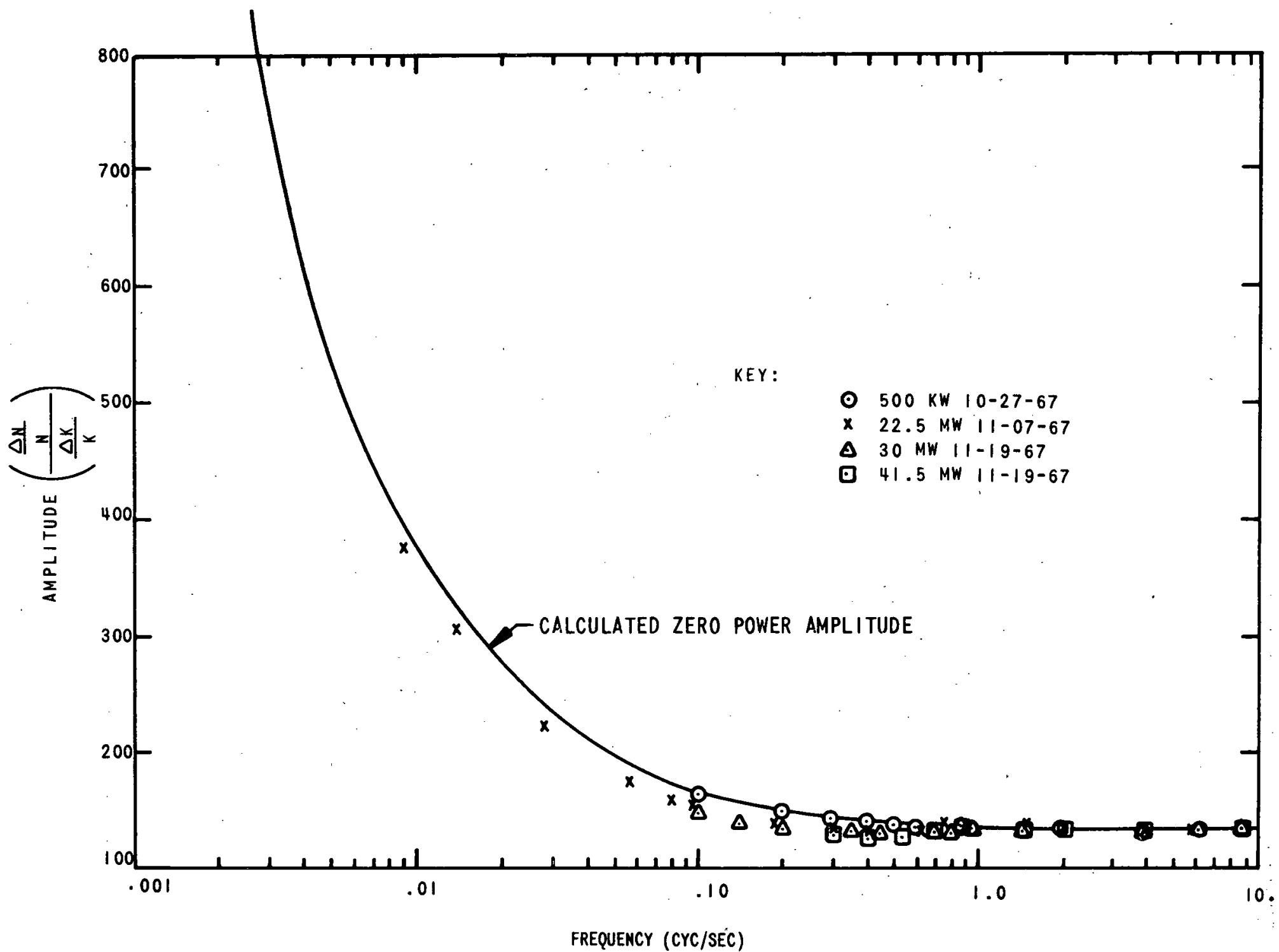

ID-103-K5115 Rev. 1

Fig. 6. Amplitude of EBR-II Transfer Function with Control Rods Banked at 12.75 in. 


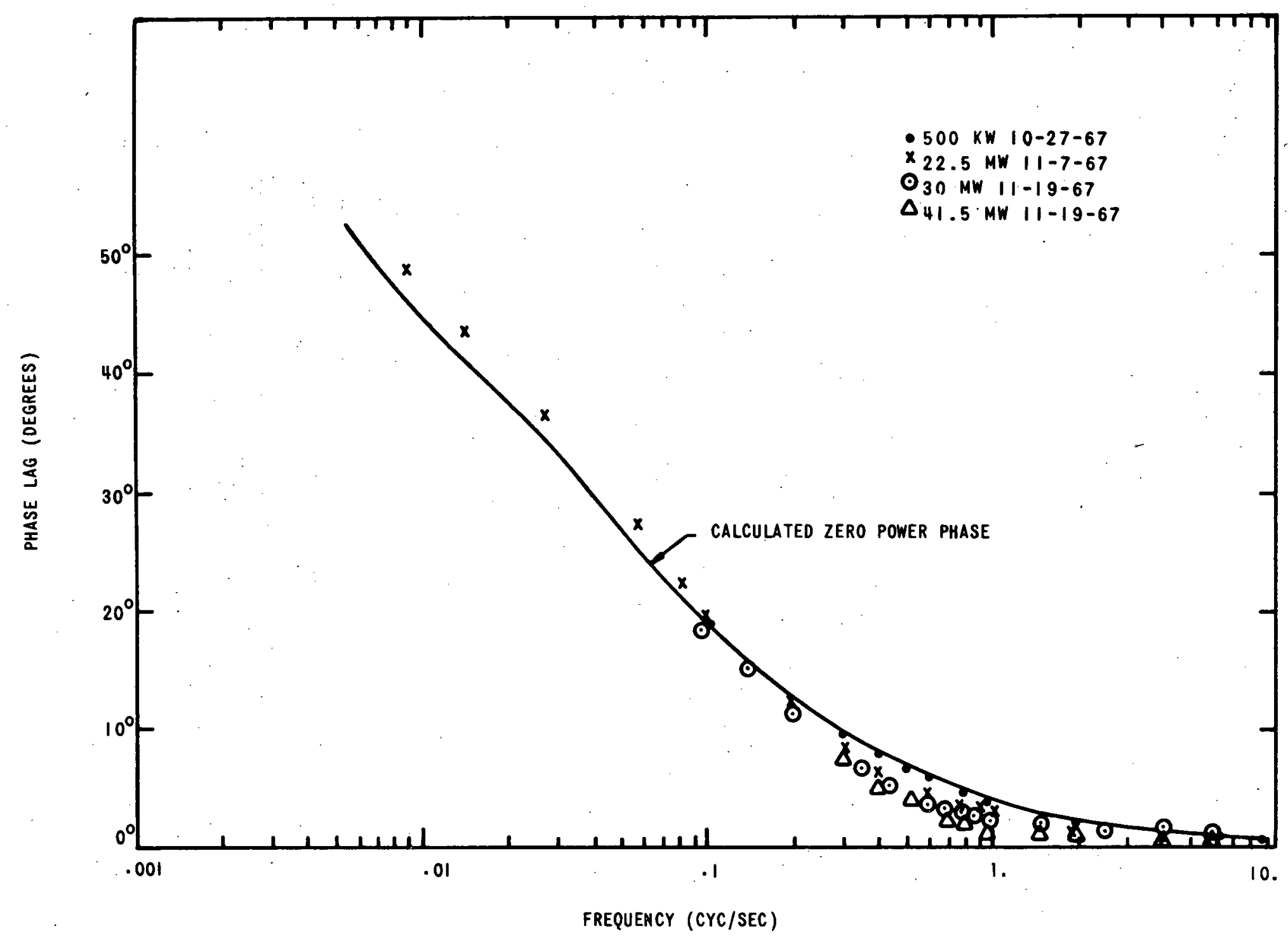

ID-103-K5116 Rev. 1

Fig. 7. Phase Lag of EBR-II Transfer Function with Control Rods Banked at 12.75 in. 


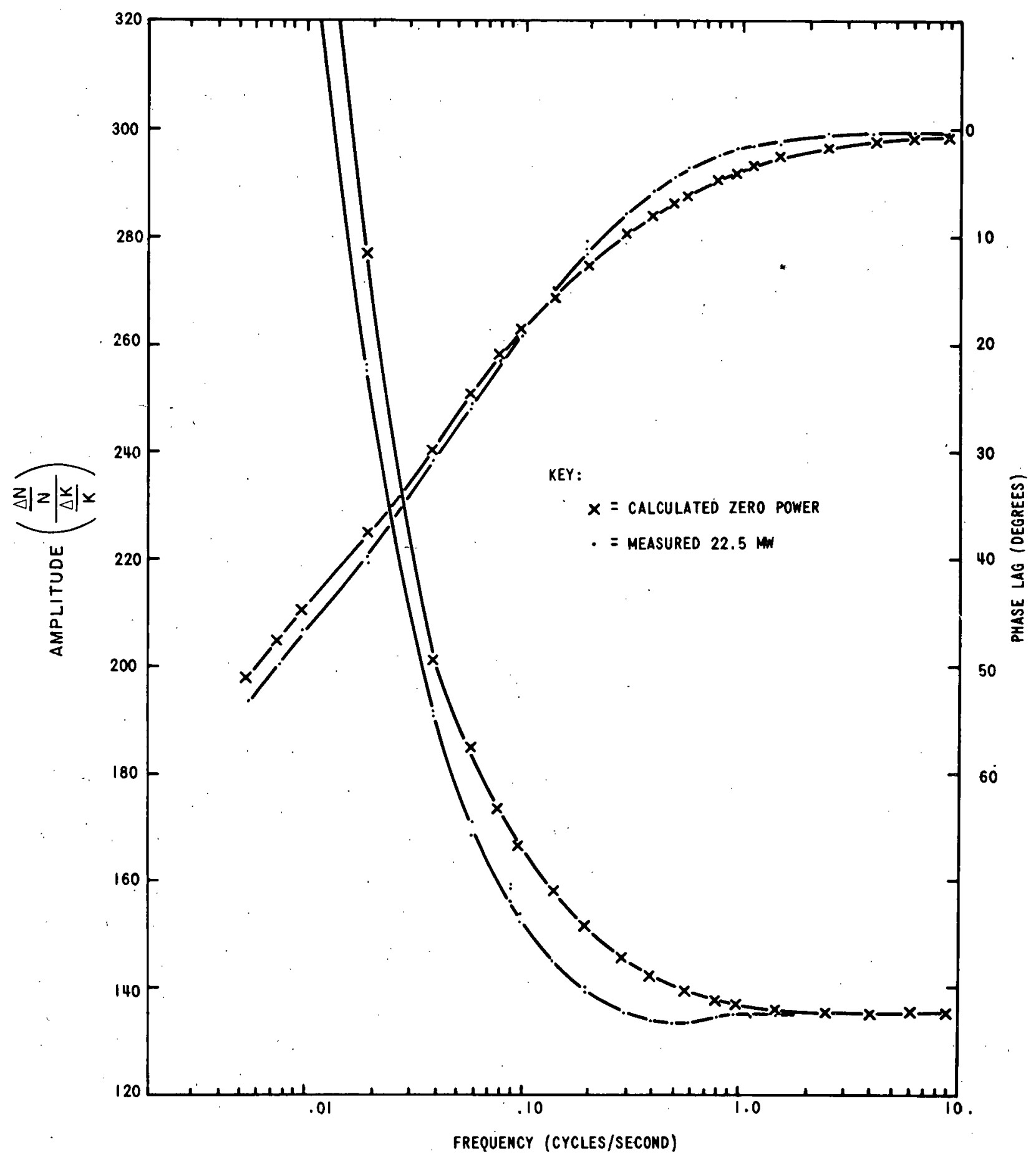

ID-103-K5117 Rev. 1

Fig. 8. Comparison of EBR-II 22.5-MW and Zero-power Transfer Functions 


\section{ROD-DROP EXPERIMENTS}

For the rod-drop experiments, one of the standard control rods has been replaced by a rod containing stainless steel rather than fuel. Upon initiation of a trip signal, this rod is ejected downward out of the core through a total stroke of $14 \mathrm{in.}$ Through the last 6 in. of travel, the rod is decelerated and brought to rest by a standard dashpot. As a result of rod ejection, the reactivity of the reactor is reduced by about 12 Ih in $0.28 \mathrm{sec}$.

The data taken in a rod-drop experiment are the rod position versus time and the power level versus time as read by an ion chamber. With these data and a rod-reactivity calibration at hand, the data processing to obtain feedback is straightforward. One merely converts the position and power data to digital data, as discussed in Section II. The data are punched on cards and fed as input to an inverse kinetics code on the CDC-1604 computer. This code calculates the total reactivity versus time from the power data, and then using the rod position data and calibration, it.subtracts the rod reactivity to obtain the feedback.

The procedures to reduce the influence of noise have been twofold. The higher-frequency noise is effectively averaged out by using a high sampling rate, 200 samples per second. As shown later in Fig. 13, although the noise causes a spread of about $0.1 \not$ in the data, there are enough points to define an accurate average with respect to the highfrequency noise. To further reduce the high-frequency noise, but more especially to average out the slower drifts, the procedure used in most cases was to average the results of three consecutive rod drops. It would be advantageous to extend this further to perhaps ten drops, but this would consume considerably more reactor time and would further aggravate the already difficult data-processing problem. One could consider larger numbers of rod drops when better on-line data-processing equipment is available.

Two groups of rod-drop experiments were done. Three 500-kW drops at the 13-in. rod-bank position and three at the 11-in. rod-bank position were conducted for calibration. Three drops each were conducted at 25 , 35 , and $45 \mathrm{MW}$ at a 13-in. rod-bank position, and then three drops at $45 \mathrm{MW}$ and an $11-i n$. rod-bank position. Of these, one 500-kW, 13-in. drop and one 25-MW, 13-in. drop were voided because of errors in data acquisition.

The second group of rod-drop experiments were chosen to correspond to a set of oscillator experiments carried out at the same power level and rod-bank position, at about the same time. Three drops were conducted at $500 \mathrm{~kW}$ and an 11 -in. rod-bank position for rod calibration. Then, at the same rod-bank position, a set of three drops was conducted at each of three power levels: $22.5,30$, and $41.4 \mathrm{MW}$. 
The reactivity calibrations of the stainless steel rod for the 11 and 13-in. rod-bank positions are plotted in Figs. 9 and 10 . We have plotted the points from each of the three and two drops, respectively, as + marks and the averages as a connected curve. There is some spread, but the spread is not excessive. The data define the calibration fairly accurately.

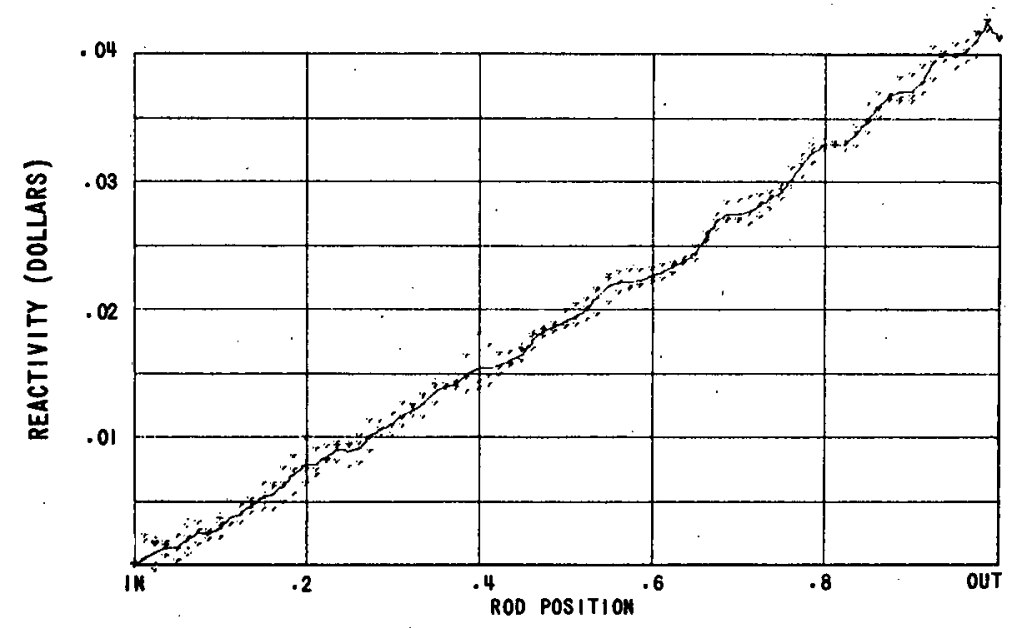

ID $-103-\mathrm{K} 5118$

Fig. 9. Reactivity Calibration of Stainless Steel Rod at 11 -in. Rod-bank Position

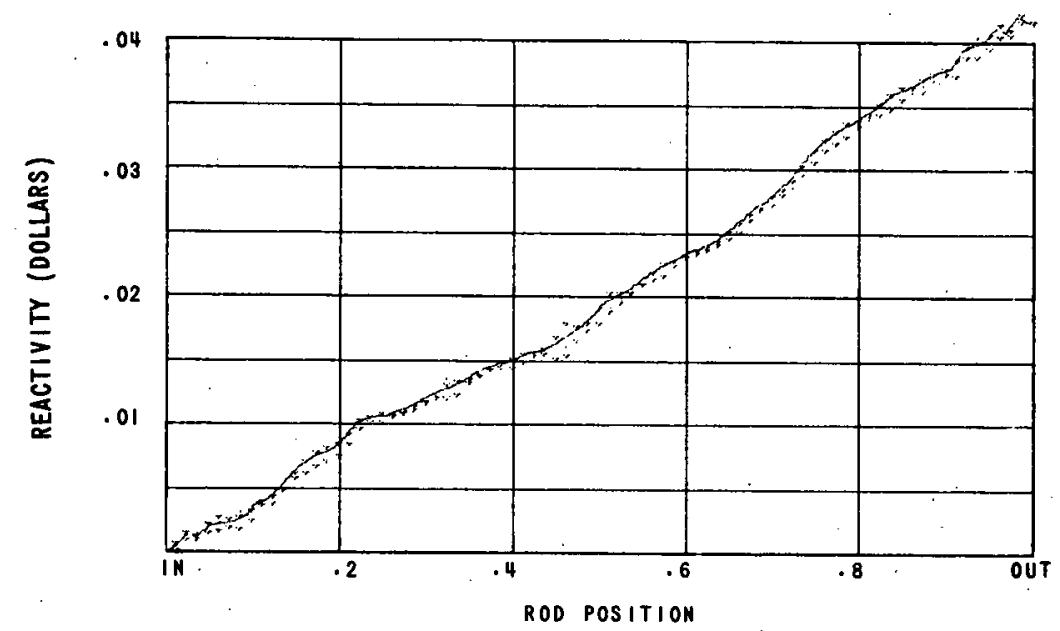

ID $-103-\mathrm{K} 5118$

Fig. 10. Reactivity Calibration of Stainless Steel Rods at 13-in. Rod-bank Position

The following test was performed to partially check the precision of the calibration, the validity of the delayed-neutron data used in the inverse kinetics calculation, and the computer program to calculate feedback. The procedure involved running the $500-\mathrm{kW}$ data, used to calibrate the rod, through the feedback code. Figures 11 and 12 indicate that the result averaged over the noise is zero feedback, as expected. 


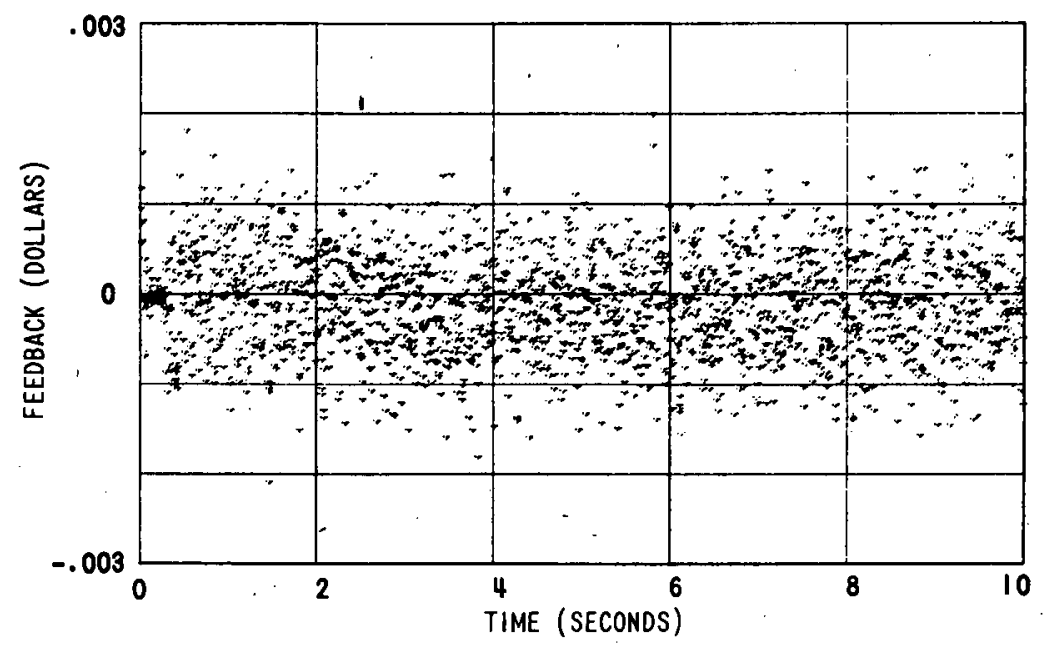

ID $-103-K 5119$ Rev. 1

Fig. 11. Feedback Plot for Rod-drop Experiment for Run 26B at $500 \mathrm{~kW}$ with Rod Banked at 11 in.

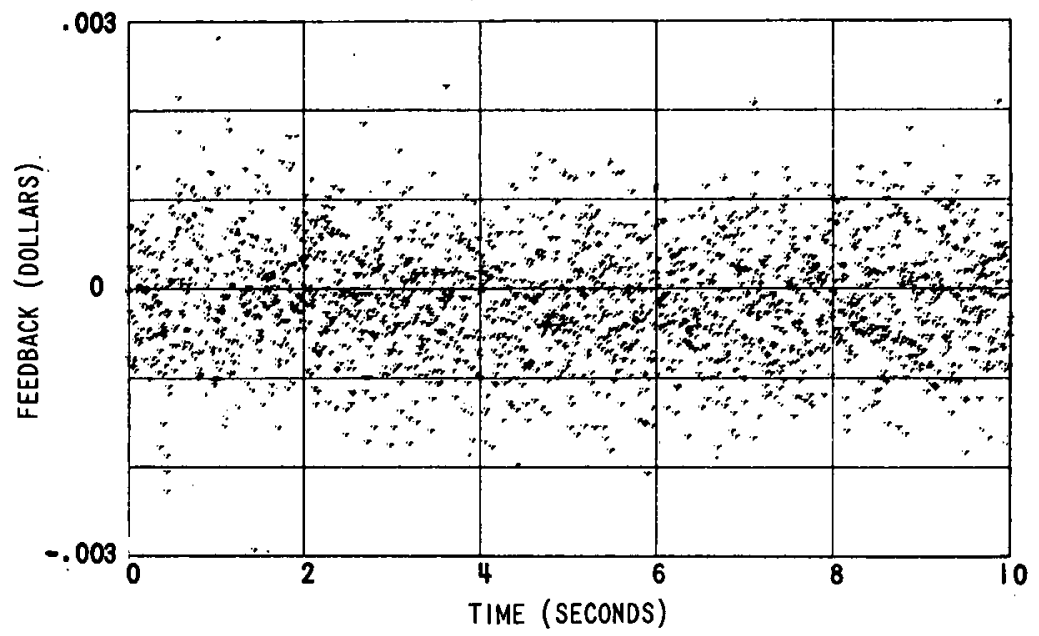

ID $-103-$ K5 119 Rev. 1

Fig. 12. Feedback Plot for Rod-drop Experiment for Run $26 \mathrm{~A}$ at $500 \mathrm{~kW}$ with Rod Banked at 13 in.

The average feedback for each condition of power level and rod position is plotted in Figs. 13-18. To illustrate the reproducibility of the feedback from one rod drop to the next, the results from each of the three individual rod drops at $41.4 \mathrm{MW}$ are compared in Fig. 19. The reproducibility is felt to be adequate to define a good average from three runs. A smooth curve drawn through the points is probably accurate to $\pm 0.02 \not$ after the first $0.5 \mathrm{sec}$. During the first $0.5 \mathrm{sec}$, the uncertainty is a little greater because the feedback is increasing too rapidly for 200 samples per second to define an accurate average. 


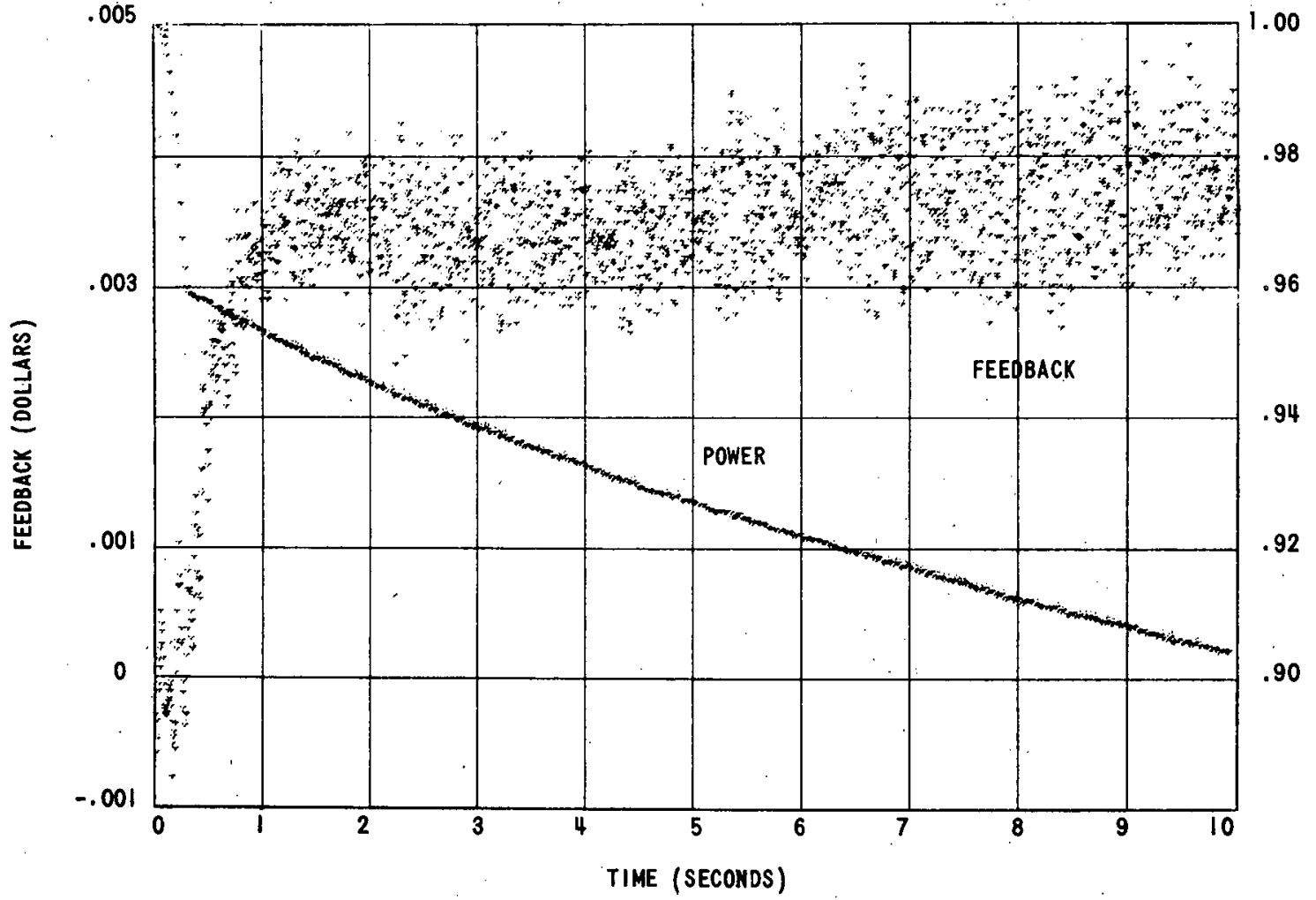

ID $-103-\mathrm{K} 5120$

Fig. 13. Feedback and Power Plots for Rod-drop Experiment for Run 26B at $22.5 \mathrm{MWt}$

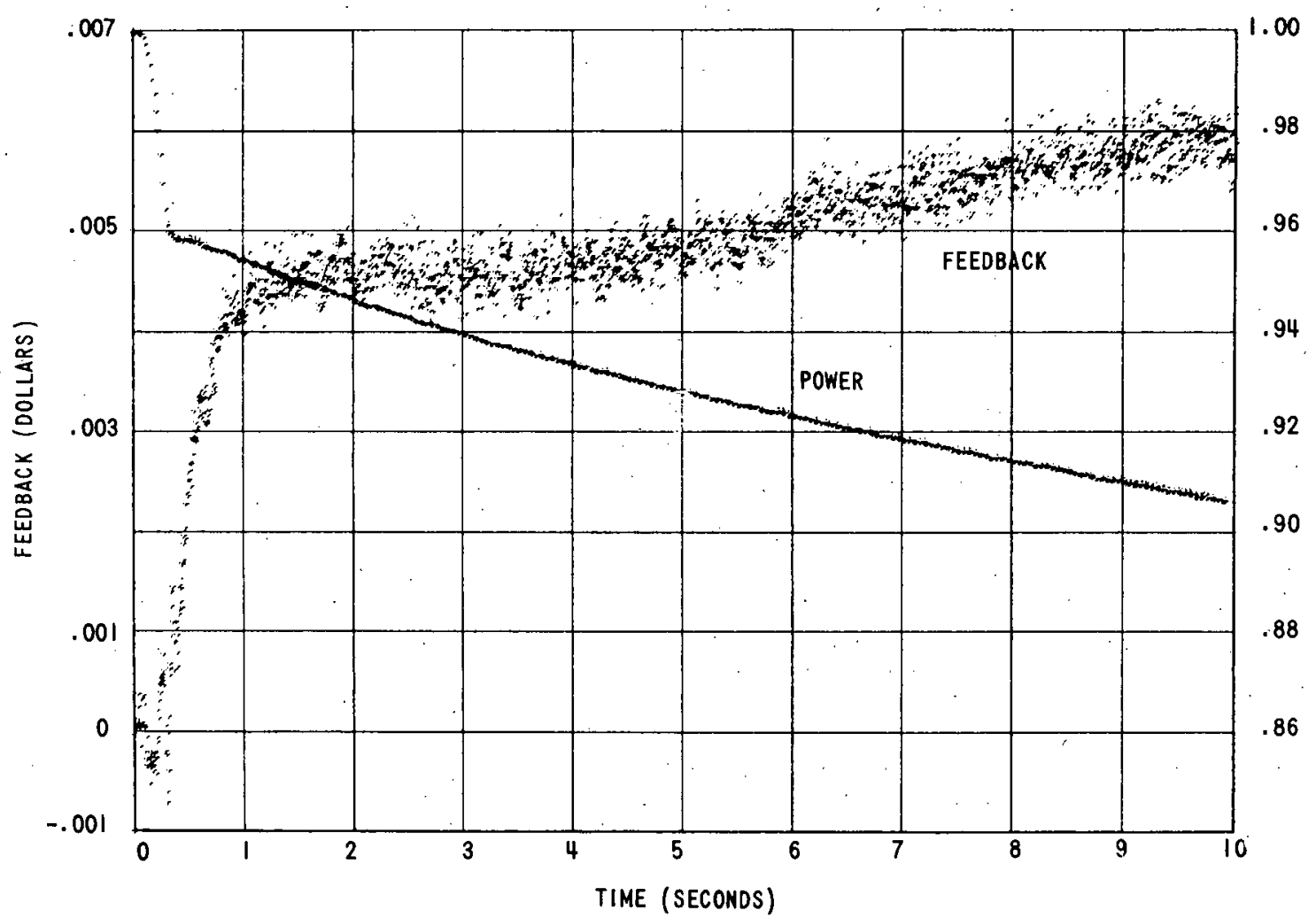

Fig. 14. Feedback and Power Plots for Rod-drop Experiment for Run $26 \mathrm{~B}$ at $30.0 \mathrm{MWt}$ 


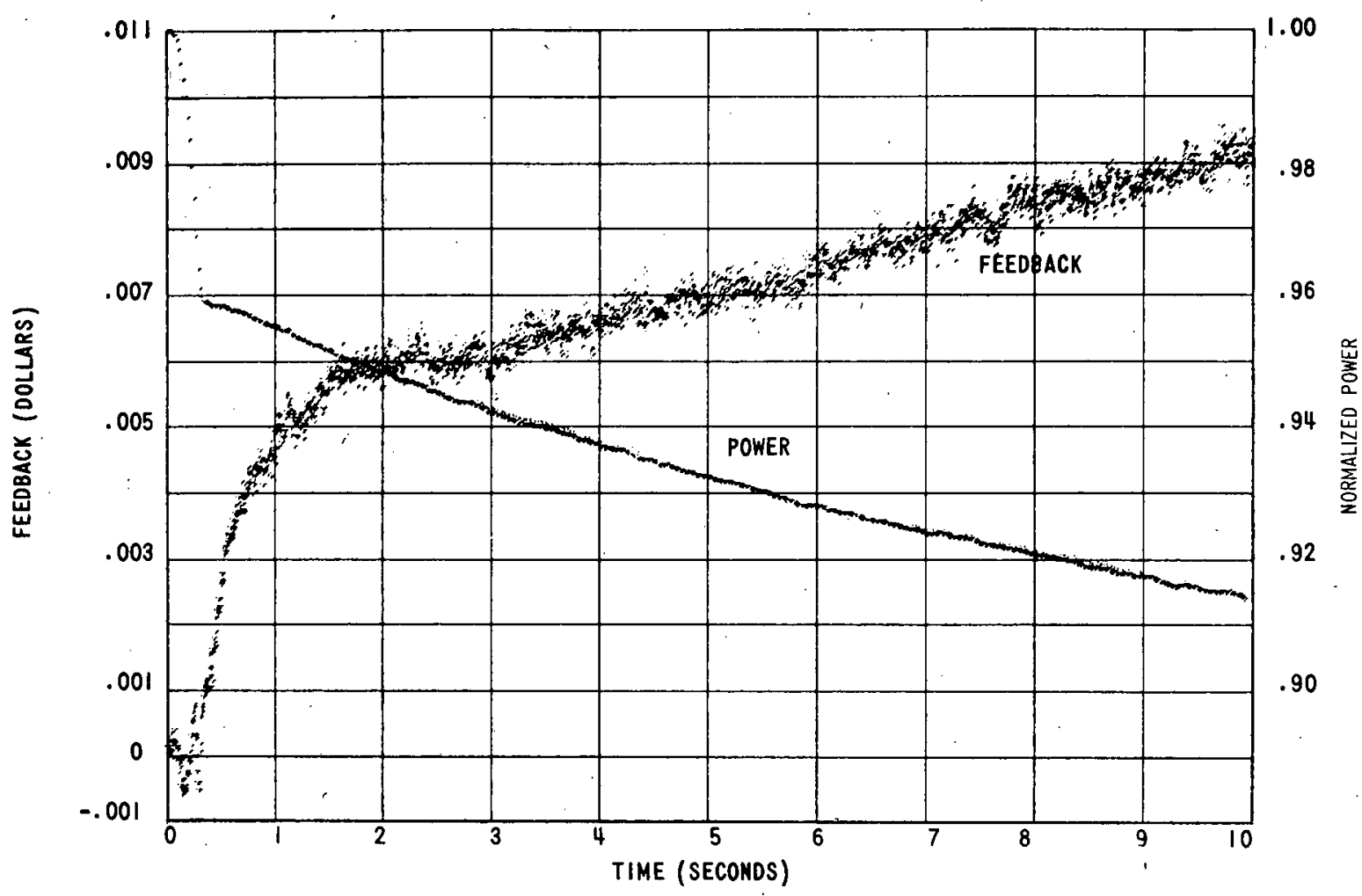

ID-103-K5122 Rev. 1

Fig. 15. Feedback and Power Plots for Rod-drop Experiment for Run 26B at $41.4 \mathrm{MWt}$

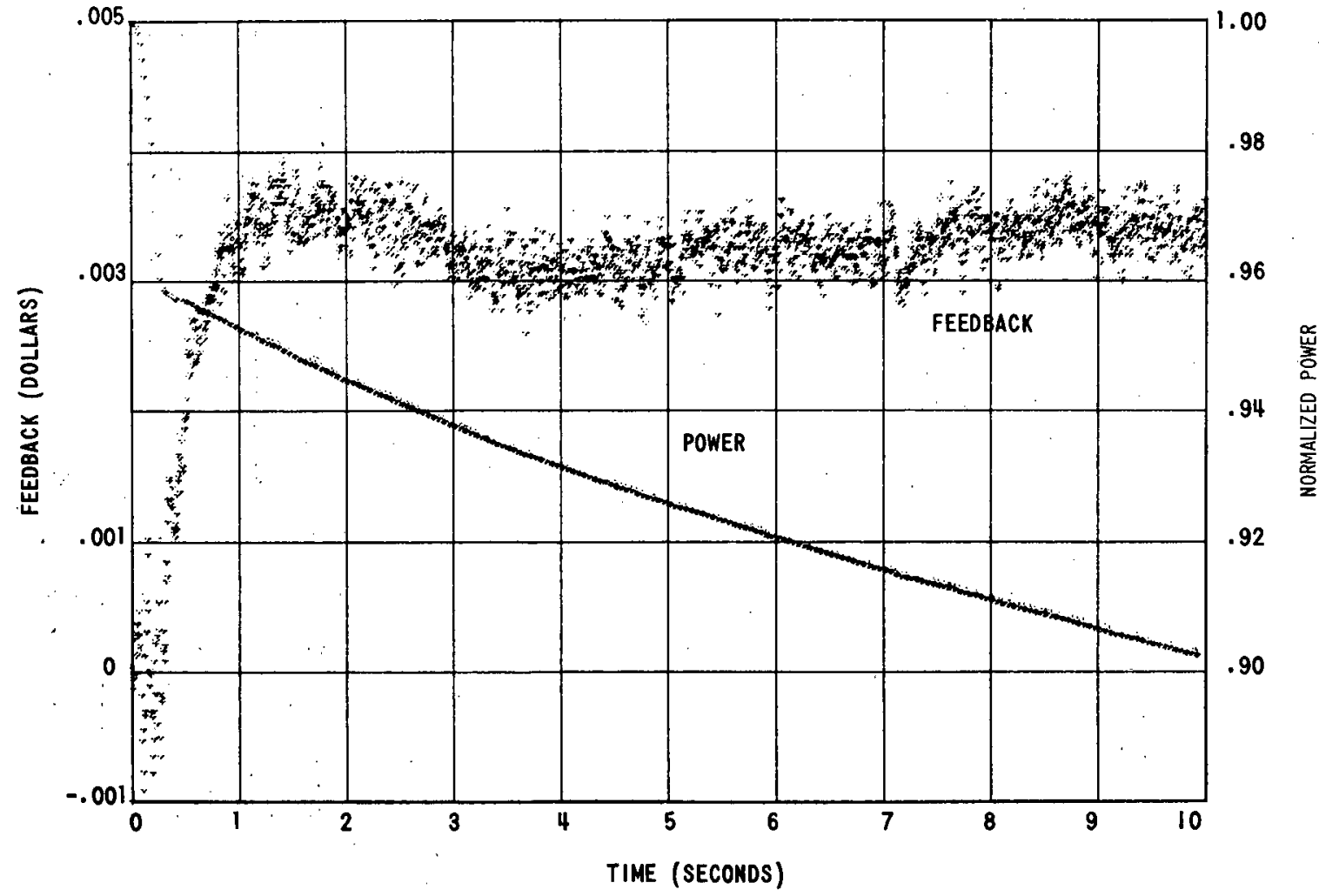

ID $-103-K 5123$

Fig. 16. Feedback and Power Plots for Rod-drop Experiment for Run 26A at 25.0 MWt 


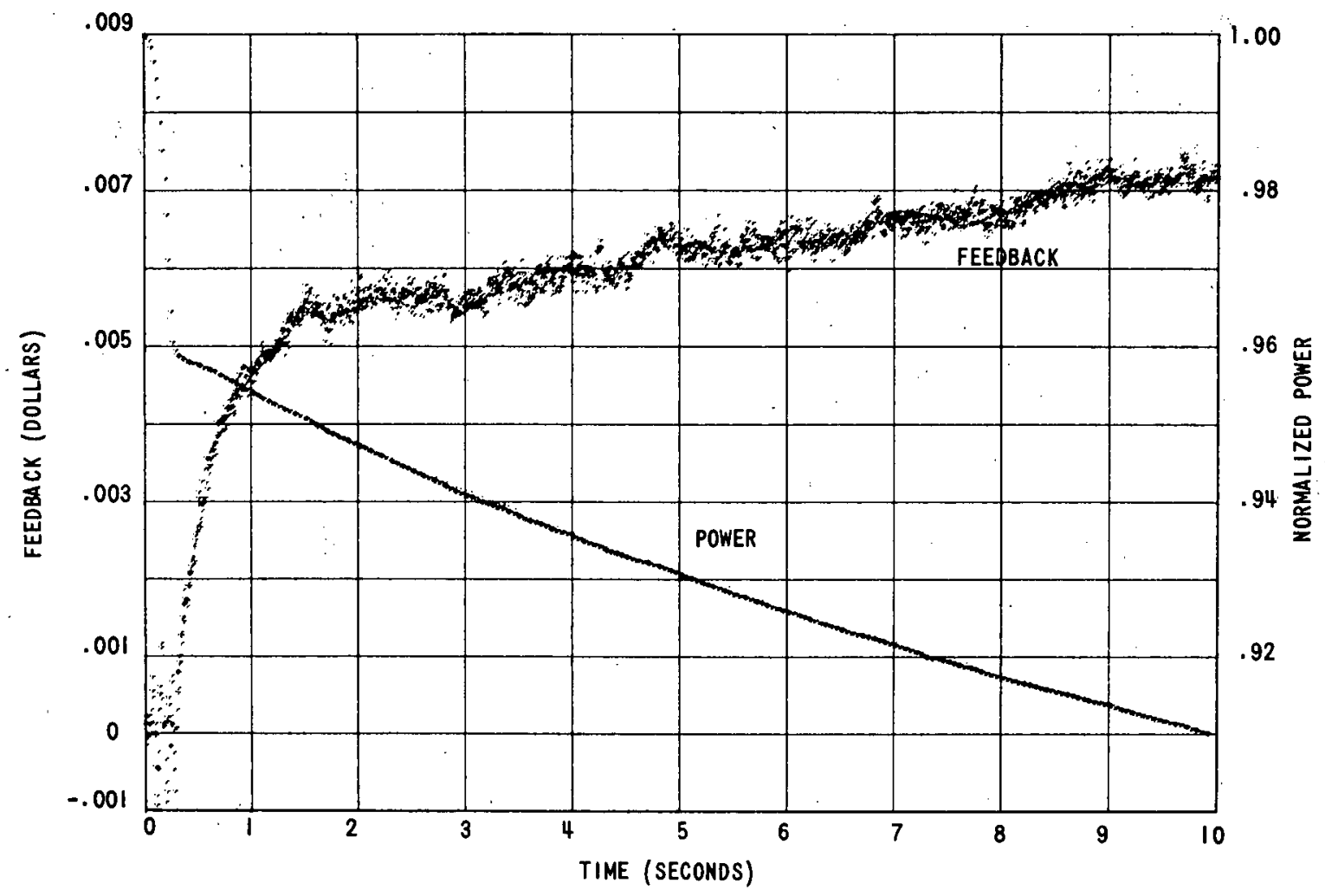

ID -103-K5124

Fig. 17. Feedback and Power Plots for Rod-drop Experiment for Run $26 \mathrm{~A}$ at $35.0 \mathrm{MWt}$

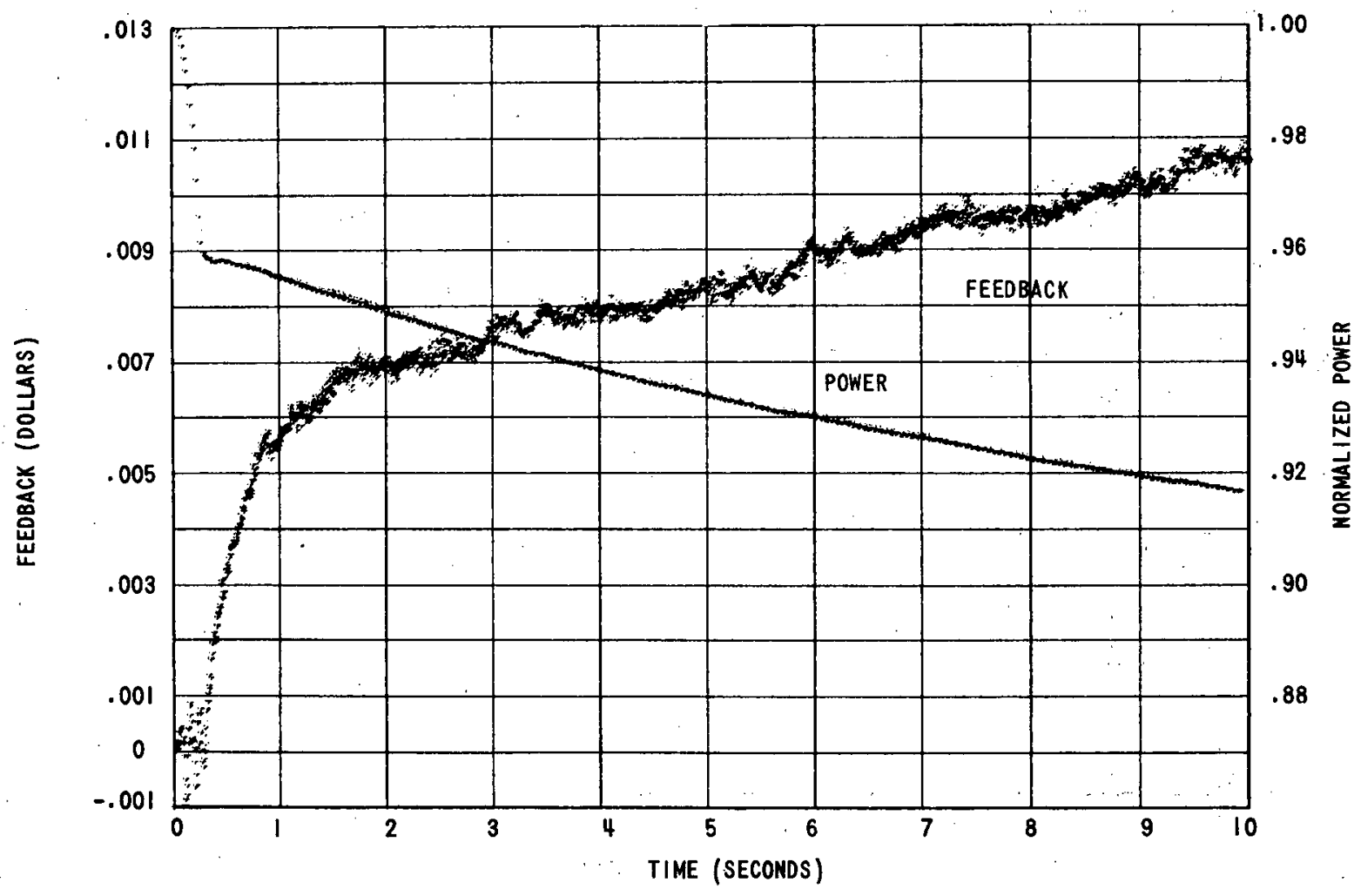

ID $-103-\mathrm{K} 5125$

Fig. 18. Feedback ànd Power Plots for Rod-drop Experiment for Run $26 \mathrm{~A}$ at $45.0 \mathrm{MWt}$ 




ID $-103-K 5126$

Fig. 19. Feedback Plot for Rod-drop Experiment for Run 26B at 41.4 MWt with Three Rod Drops Used for Average 


\section{THE FEEDBACK FUNC TION}

Because of some of the difficulties mentioned in Section I, we have taken the following approach to analysis of the data. The body of experimental data is considered as a whole. An estimation is made of the possible additional errors that have not yet been corrected, and these are tried to see if they can resolve some of the conflicts. The result is then a set of feedback functions determined from a combination of experiment, theory, and judgment. The results must not be regarded any longer as completely experimental in the accepted sense of the word.

Under these conditions, it is difficult to place error limits on the feedback function. There is reasonably consistent agreement on the prompt components. For frequencies greater than $0.1 \mathrm{~Hz}$, the error on a Nyquist plot in the amplitude of $\mathrm{H}$ is probably less than $\pm 10 \%$. The delayed components are less well defined, and below $0.1 \mathrm{~Hz}$, the amplitude may be in error by $\pm 50 \%$ and the phase by $\pm 30^{\circ}$. Considerable judgment is required in estimating both the feedback function and the uncertainty. If one wishes to pin down the feedback function more accurately and reduce the degree of the judgment factor, then major improvements in the experimental equipment must be made, as discussed in Section VI.

We develop the feedback function from three points of view: first, that derived mainly from the oscillator results; second, that derived mainly from the rod-drop analysis; and finally, a compromise based on both, with due regard to assumed errors in the two sets of data.

\section{A. Feedback Function from Oscillator Data}

A fundamental problem in determining the feedback from oscillator experiments is that one does not know accurately the reactivity worth of the oscillator at the reactor power conditions. One could measure the worth by doing oscillator tests at low power where there is not feedback. However, the worth of a rotating rod is dependent upon the flux gradients, which may shift slightly from low to high power. Hence this method is not likely to be reliable.

Another procedure that has been used is to normalize the transfer function (equivalent to determining the rod worth and phase) to the zeropower transfer function at high frequency. This procedure assumes that the feedback is negligible at high frequency. The EBR-II oscillator has an upper frequency limit of $8 \mathrm{~Hz}$. Further, it has a natural mechanical resonance just above this point, so that in practice one must invalidate any data above about $6 \mathrm{~Hz}$. Figure 20 shows that the EBR-II feedback is far from negligible at this frequency. The approach therefore has to be taken of normalizing it not at zero, but to what we think it should be at $6 \mathrm{~Hz}$. There are reasons to believe that this can be done with reasonable assurance. 
One can be quite certain that at $6 \mathrm{~Hz}$, the only feedback effects that can respond are those associated with the temperature of the fuel and the coolant in the core. From heat-transfer calculations, * we have verified that the fuel and core sodium have feedback functions that are well approximated by the simple form

\section{$\frac{A}{1+i \omega \tau}$}

with time constants $\tau$ in the range of $0.2-0.4 \mathrm{sec}$. Thus, with A positive, one expects the $6-\mathrm{Hz}(\omega \approx 38)$ feedback function point to lie in the fourth quadrant near the imaginary axis. One expects further that the feedback from $6 \mathrm{~Hz}$ down to at least $1 \mathrm{~Hz}$ will resemble the beginning of a half-circle in the fourth quadrant.

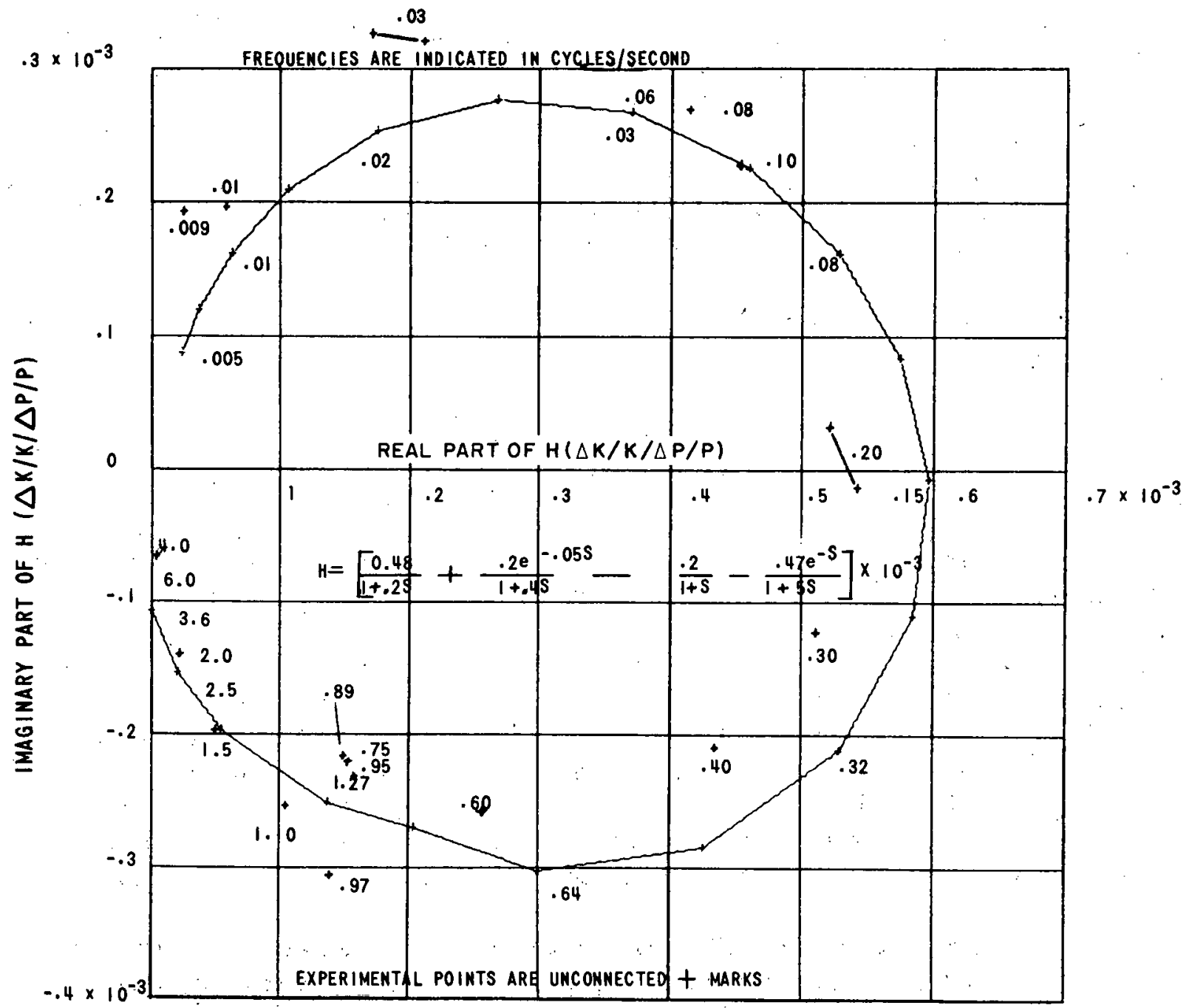

ID -103-K5127 Rev. 1

Fig. 20. Nyquist Plot of Oscillator Feedback Function for Run 26B at 22.5 MWt

* See Appendix A. 
With these reasonable expectations, one can proceed iteratively. First, the $6-\mathrm{Hz}$ normalization point is estimated and the feedback is calculated from the normalized transfer function and the zero-power transfer function. Then one finds the best possible fit over the entire frequency range using a function of the form

$$
H=\sum_{i} \frac{A_{i} e^{-s T_{i}}}{1+s \tau_{i}}
$$

By inspection, one now estimates whether the fit could be improved by slightly shifting the normalization point. This can be repeated if necessary until one has a normalization that is consistent with the best guess for the feedback function.

While we defend this procedure as the best one with the available equipment, it has some deficiencies, and we have suggested improved equipment in Section VI to eliminate some of the uncertainties.

In the present section we ignore the problem of oscillator-rod bowing, assuming that the measurements are valid and fit the data as well as possible with a feedback function of the form of Eq. 7 .

An excellent fit was obtained in this manner for the Run $26 \mathrm{~B}$ data at $22.5 \mathrm{MW}$ with the feedback function

$$
H=10^{-3}\left[\frac{0.48}{0.2 s+1}+\frac{0.2 e^{-0.05 s}}{0.4 s+1}-\frac{0.2}{s+1}-\frac{0.47 e^{-s}}{5 s+1}\right]
$$

Figure 20 compares the measured curve with this model. The agreement is within the experimental accuracy for every frequency point. One expects that at least the prompt components of $H$, those due to fuel and coolant expansion, should be approximately proportional to power level. Figures 21 and 22 compare the measured feedback at 30 and $41.4 \mathrm{MW}$ with the scaled-up feedback function of Fig. 20. The agreement is good. However, this really only tests the scaling of the prompt components because the 30- and 41.4-MW data extend down only to about 0.1 Hz. Because of the behavior of the steady-state power coefficient, one does not expect the delayed components (mostly bowing) to be proportional to power level.

The results for the 12.75 -in. rod-bank position are also given in Figs. 21-22. Here again we have plotted the same feedback function, which fits the data reasonably well. Some improvement could be obtained by fitting each set of data with a different feedback function, but this would not be very meaningful and has not been done. 


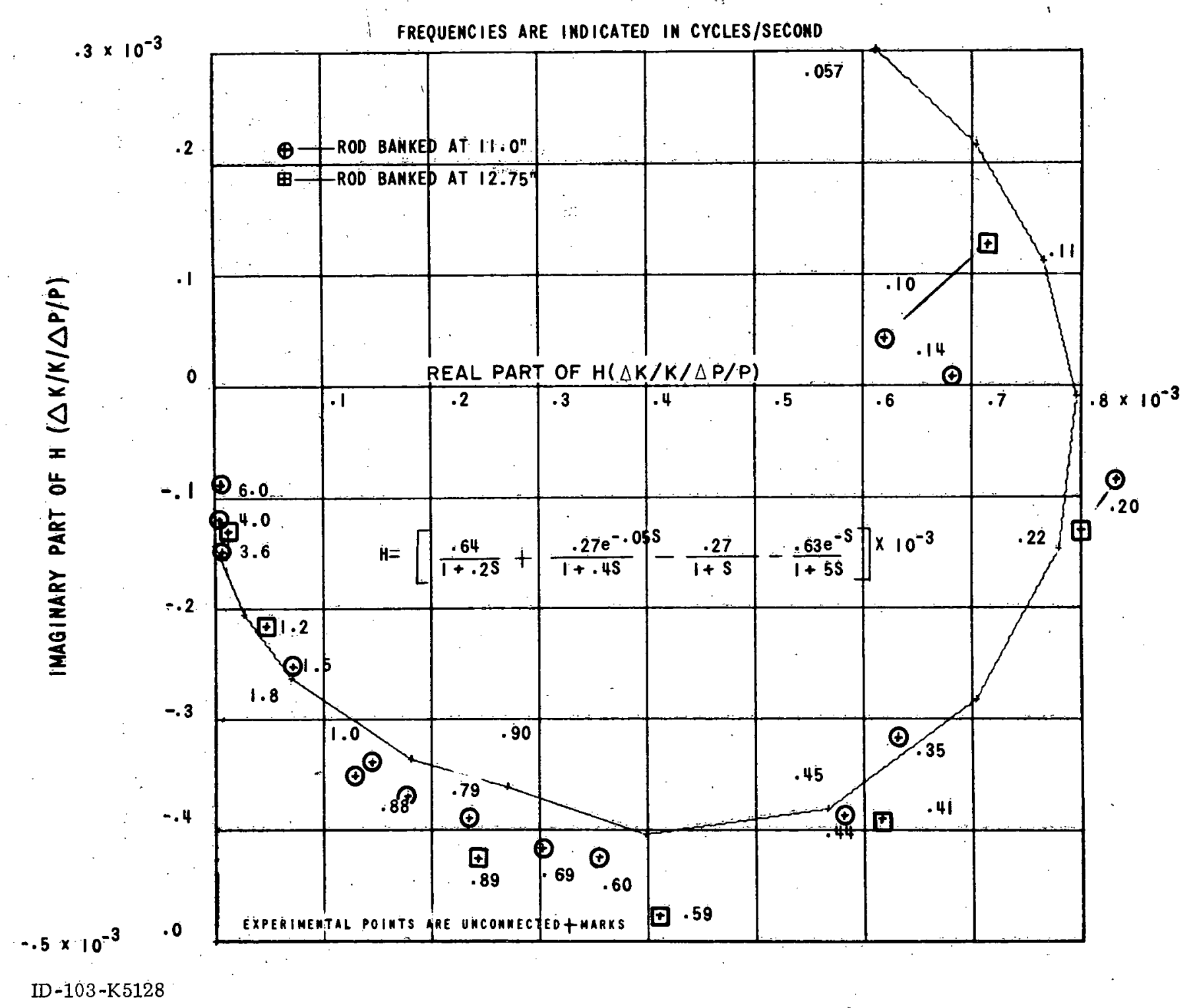

Fig. 21. Nyquist Plot of Oscillator Feedback Function for Run $26 \mathrm{~B}$ at $30.0 \mathrm{MWt}$ 


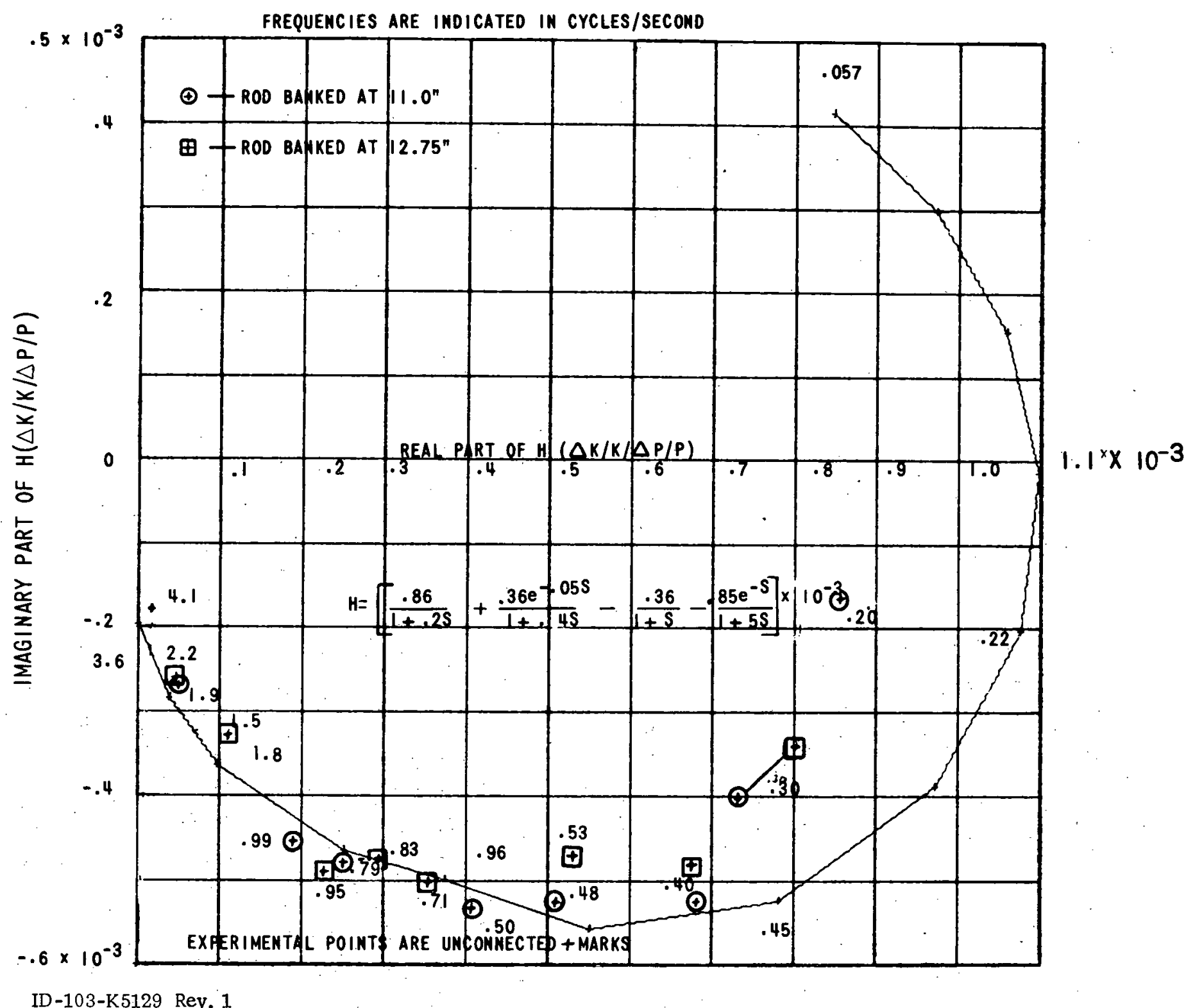

Fig. 22. Nyquist Plot of Oscillator Feedback Function for Run $26 \mathrm{~B}$ at $41.4 \mathrm{MWt}$ 
Some features of the data are not completely consistent with our picture of the feedback mechanisms. At $41.4 \mathrm{MW}$, the experimental points follow the model fairly well at high frequency but fall off to less positive values at 0.3 and $0.2 \mathrm{~Hz}$. This is opposite to what would be expected. With increasing power, the delayed components (which influence the curve at low frequency) are believed to have a tendency to saturate or disappear as the expansion and bowing effects tighten the core. This would cause the feedback to be stronger at these frequencies than predicted by a model scaled up linearly from 22.5 to $41.4 \mathrm{MW}$. The deviation from expected behavior could be the result of a complicated oscillator-rod bowing effect. We know the rod begins to bind just below this frequency at $41.4 \mathrm{MW}$. (However, see Section V.C on the correction for rod bowing at $22.5 \mathrm{MW}$. Our simple model of rod bowing indicates a correction in the wrong direction to explain this deviation.)

The comparison between the 11 - and 12.75-in. rod-bank positions is also surprising. There is no significant or consistent difference in results between the two positions. Independent estimates by both the Idaho and Illinois EBR-II analysts indicate that there should be about a $15 \%$ stronger (more negative) power coefficient at the 11 -in. position than at the 12.75-in. position. This is not seen here or in the rod-drop experiments. One possible explanation is that we use the same normalization at both positions. Perhaps the rod worth is slightly different at the two rod-bank positions and there should then be a different normalization. We have no way of checking this experimentally.

There are other reasons to suspect that the oscillator data do not give quite the true picture of the feedback function. The model of Fig. 20 has essentially a zero steady-state power coefficient. To be in agreement with the power-coefficient measurements of October 27, 1967, the curve should end at zero frequency on the real axis somewhere between $0.1 \times 10^{-3}$ and $0.2 \times 10^{-3}$ : The experimental data go down to a frequency of $0.0057 \mathrm{~Hz}$. If the data could have been extended to lower frequencies, the curve might have curled back and ended at the proper steady-state coefficient. It would, in fact, be possible to add a fifth term with a long time constant to the model that would accomplish that effect. In this sense, one can reason that there is not necessarily a conflict between the oscillator and steadystate measurements.

The main disagreement is with the rod-drop experiments, which seem to indicate that the oscillator curve should already curl in toward the steady-state point at the lower measured frequencies and should not approach the imaginary axis as they do in Fig. 20. This conflict and some possible corrections to the data to relieve it are developed further in Section V.C. 
B. Feedback Function from Rod-drop Experiments

Let $P(t)$ be the power normalized to unity at $t=0$. Call the feedback $F B(t)$. If one assumes the feedback function $H$ has the form of Eq. 7 , it can be shown that $F B(t)$ is then given by

$$
F B(t)=\sum_{i} \frac{A_{i} e^{-\left(t-T_{i}\right) / \tau_{i}}}{\cdot \tau_{i}} \int_{0}^{t}\left[1-P\left(t^{\prime}\right)\right] e^{\left(t^{\prime}-T_{i}\right) / \tau_{i}} d t .
$$

The procedure then for developing $H$ from the rod-drop data is to estimate the constants $A_{i}, T_{i}$, and $\tau_{i}$, substitute them into Eq. 9 along with the experimental $P(t)$, and calculate $F B(t)$. This is then compared with the experimental $F B(t)$ as obtained by solution of the inverse kinetics equations. By trial and error, one adjusts the parameters and recalculates $F B(t)$ until satisfactory agreement is obtained between the model and the experiment. With the aid of the IBM-1620 computer and a little experience, a good fit can be obtained with a few hours of effort.

An alternate procedure was tried and discarded: One can show that for feedbáck of the form considered, the feedback function $H(s)$ expressed as a function of the Laplace transform variable, $s$, is given by the ratio of the Laplace transform of $F B(t)$ to the Laplace transform of $1-P(t)$. Thus,

$$
H(s)=\frac{\int_{0}^{\infty} F B(t) e^{-s t} d t}{\int_{0}^{\infty}[1-P(t)] e^{-s t} d t}
$$

In this case, the procedure is to calculate $\mathrm{H}(\mathrm{s})$ in this manner from the experimental feedback and power and then, as in the oscillator experiments, fit a model of the form of Eq. 7 to this experimental $\mathrm{H}(\mathrm{s})$. There are two points of difficulty. One is that the integrals must be extended to infinity in Eq. 10, so some procedure must be devised for extrapolating the power and feedback. The other problem is that as one goes to large values of $s$ and the denominator and numerator of $\mathrm{Eq}$. $\mathrm{l}$ become small, the large amount of noise in $\mathrm{FB}(\mathrm{t})$ compared to $1-\mathrm{P}(\mathrm{t})$ causes the denominator to become much smaller than the numerator, and $\mathrm{H}(\mathrm{s})$ diverges sometimes positively and sometimes negatively.

These two effects cause $\mathrm{H}(\mathrm{s})$ to be inaccurate at high and low ifrequencies. This means that one should try to fit the function only over the middle-frequency range. The high-frequency range corresponds to the short-time range in the time domain. There are reasons to suspect that the measured rod-drop feedback is especially inaccurate at short times. 
One has a clearer understanding of the behavior in the time domain than in the domain of the transform variable $s$. The time domain, therefore, is the one where it is easier to cope with some possible corrections to the data and arrive at a reasonable estimate of what the feedback should actually have been. We therefore abandoned the Laplace-transform approach and analyzed the data in the time domain.

After some preliminary analyses of rod-drop and oscillator data, we reached the conclusion that there were strong feedback components having time constants in the range of 0.2-0.4 sec. The heat-transfer analysis presented in Appendix A reinforced this opinion. This conclusion leads to an anomaly, however, in the fitting of the rod-drop data at very short times. Figure 23 illustrates the point. A good fit was obtained to these data over the time range of 1-10 sec using 0.2- and 0.4-sec time constants for the prompt terms. The figure shows that under these conditions the model appears to greatly overestimate the feedback during the first 0.5-sec interval. Figure 23 also indicates that there is about a $0.25-\mathrm{sec}$ time delay during which there is no feedback. This does not seem a physical possibility. Two other explanations have been given serious consideration.

One effect, which at first seems credible, is that there might be a fairly strong positive coefficient with a very short time constant, which is just sufficient to cancel the strong negative coefficients having $0.2-$ to $0.4-\mathrm{sec}$ time constants for the first $0.25 \mathrm{sec}$. After that, the stronger negative coefficients take over and produce the observed sharp rise in feedback. There are two strong reasons for discarding this as a credible possibility. The first is that heat-transfer analysis does not allow the existence of any feedback effects having time constants less than $0.15 \mathrm{sec}$. The second is that if one assumes this to be the explanation and attempts to find a set of coefficients that fit the early time data, he finds that the positive coefficient must be quite large. Further, to overcome this large positive coefficient, the $0.2-$ and $0.4-$ sec negative terms must be larger than would be required with no positive coefficient. They must be considerably larger than expected, based upon estimates of the fuel and coolant expansion feedback effects. We have thus concluded that there must be some other explanation for the apparent $0.25-\mathrm{sec}$ delay in the observed feedback.

The other possibility, which is believed to be the only credible explanation, is that the reactivity calibration of the stainless steel rod is in error. We believe that the calibration technique is accurate, but it has to be carried out at low power. Spatial changes in flux and adjoint distributions between low and high power may result in changes in the worth of the stainless steel rod. Thus the calibration, no matter how accurate, does not precisely apply at higher powers. 


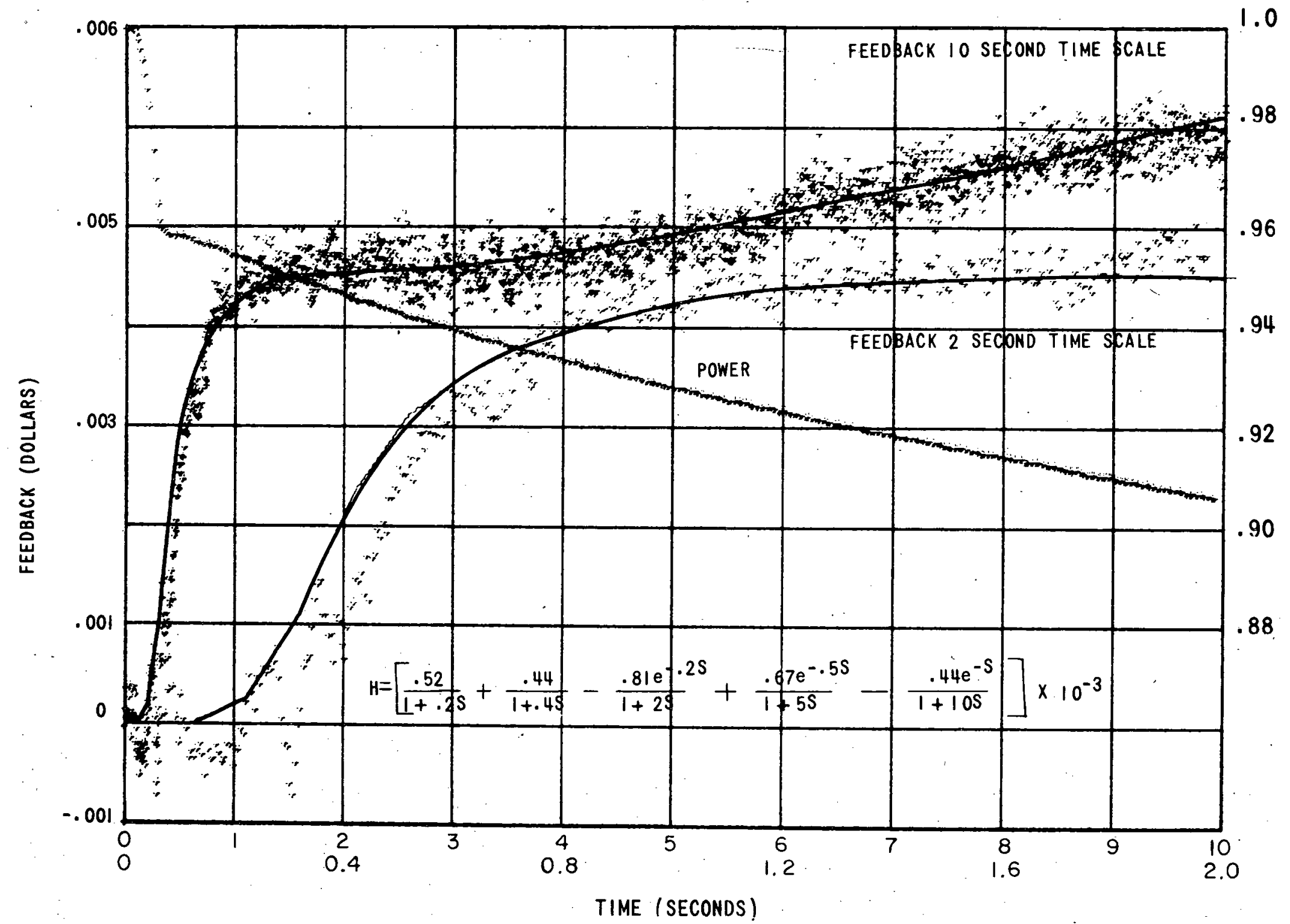

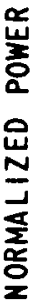

ID-103-K5130 Rey. 1

Fig. 23. Uncorrected Feedback and Model for Run 26B at $30.0 \mathrm{MWt}$ 
An error in rod calibration contributes a fictitious component to the feedback calculated from the experimental data; this component is just equal to the error in calibration. If the error can be approximated by a constant multiplying factor that applies over the entire travel of the rod, then the exror will vary from zero when the rod is in, to some maximum value when the rod has bottomed in the dashpot. This effect gives a fictitious feedback versus time, which can cancel the actual feedback while the rod is moving and can decrease the calculated feedback by a constant amount after the rod is seated in the dashpot.

A strong point in favor of this hypothesis is that the results show that the feedback appears to begin at just the instant the rod is stopped by the dashpot. This is too much of a coincidence to ignore. One cannot help but feel that the feedback is being held back by something associated with the rod motion, and a calibration error is very plausible.

Assuming that there is an error in rod calibration, a difficult question remains of what can be done to correct it. We do not believe that one can calculate the change in rod worth with power level to sufficient accuracy from fundamental principles. The calculation has to be based on experiment. One can devise an experiment in which the calibration can be done at high power. This requires a means of changing the reactivity at least twice as fast as the present system allows and is discussed further in Section VI.

For the present purpose, which is to deduce the feedback function in Run 26, it is not feasible to go back to Run 26 and do more experiments. The conditions existing in Run 26 could no longer be reproduced reliably, even if one were willing to sacrifice reactor operating time to do so. The only procedure that has any hope of success is to make whatever correction is necessary to remove the anomaly. Thus, using the model of a calibration error, we change the calibration and recalculate the "experimental" feedback. We then see if it is possible to fit the revised feedback with a reasonable feedback function. Actually, this is completely analogous to the normalization of the high-frequency oscillator data to a value consistent with the feedback model.

In this procedure, we do not treat each experiment completely arbitrarily, but try to make changes that seem consistent with the entire set of data. One would expect that if the rod calibration changes with power, the change would be more or less proportional to the power level or perhaps to the power-reactivity decrement. We have not followed a rigid procedure. We considered calibration errors of $1,2,3$, and $4 \%$ and found that the feedback fits could be markedly improved by assuming the calibration errors given in Table I. Further improvement could have been obtained by considering intermediate values of calibration error, but it was not believed of any value to attempt to really optimize this correction. We do consider it significant that this procedure led us to a set of correction factors that are 
an increasing function of power level and believe that making this correction, even though its foundation is not extremely sound, has resulted in estimated feedback functions that are more likely to be closer to the truth.

TABLE I. Assumed Calibration Errors

\begin{tabular}{cc|cc}
\hline Power (MW) & Error (\%) & Power (MW) & Error (\%) \\
\hline 22.5 & 1 & 35 & 3 \\
25 & 2 & 41.4 & 4 \\
30 & 2 & 45 & 4 \\
\hline
\end{tabular}

The results are presented graphically in Figs. 24-31, where we have plotted the corrected experimental feedback, the normalized power, and the feedback from the model. Also shown on each figure is the feedback function that corresponds to the plotted curve. The fits are quite good over the entire time range.

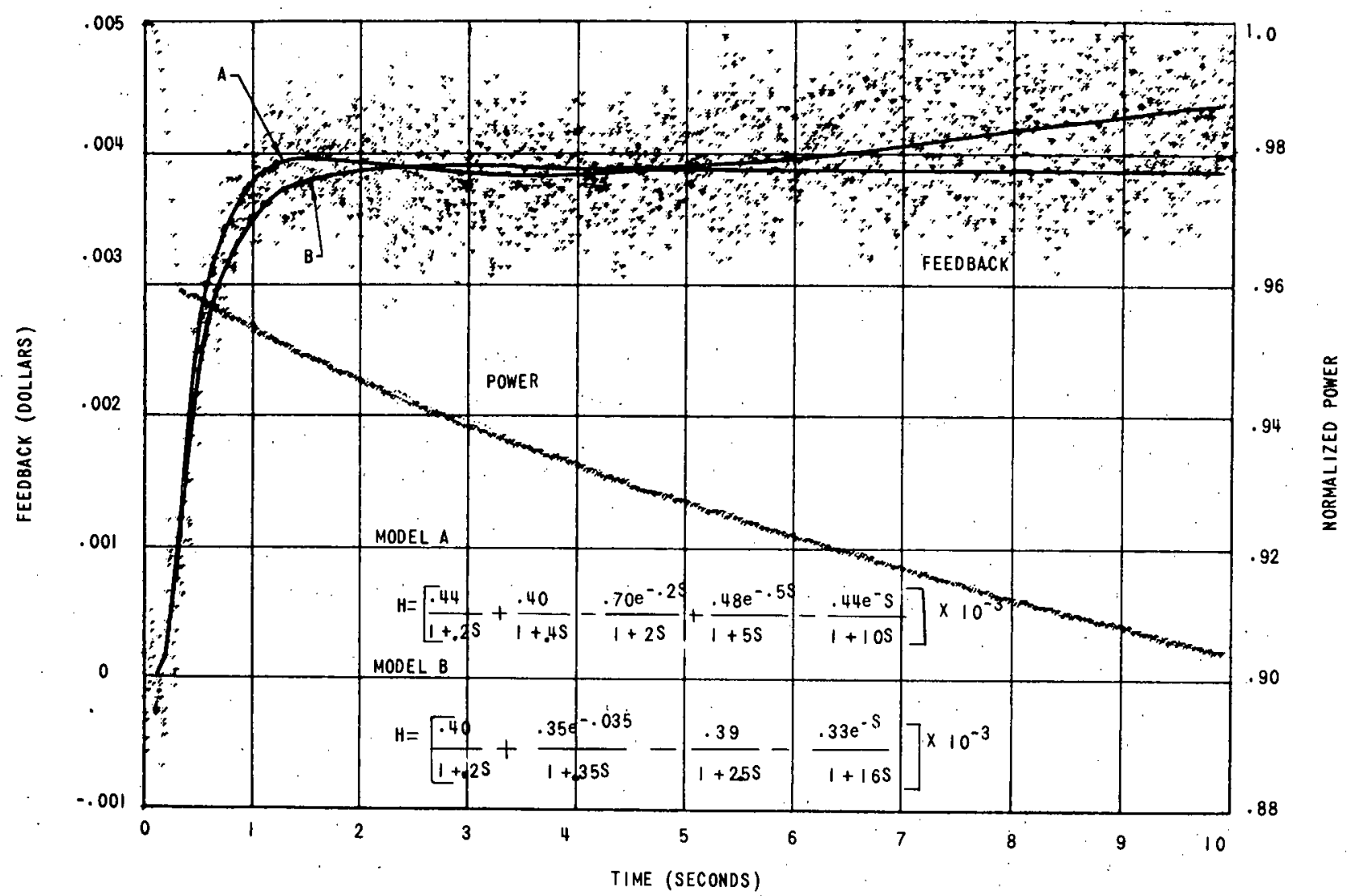

ID-103-K5131

Fig. 24. Corrected Feedback and Model for Run 26B at 22.5 MWt 


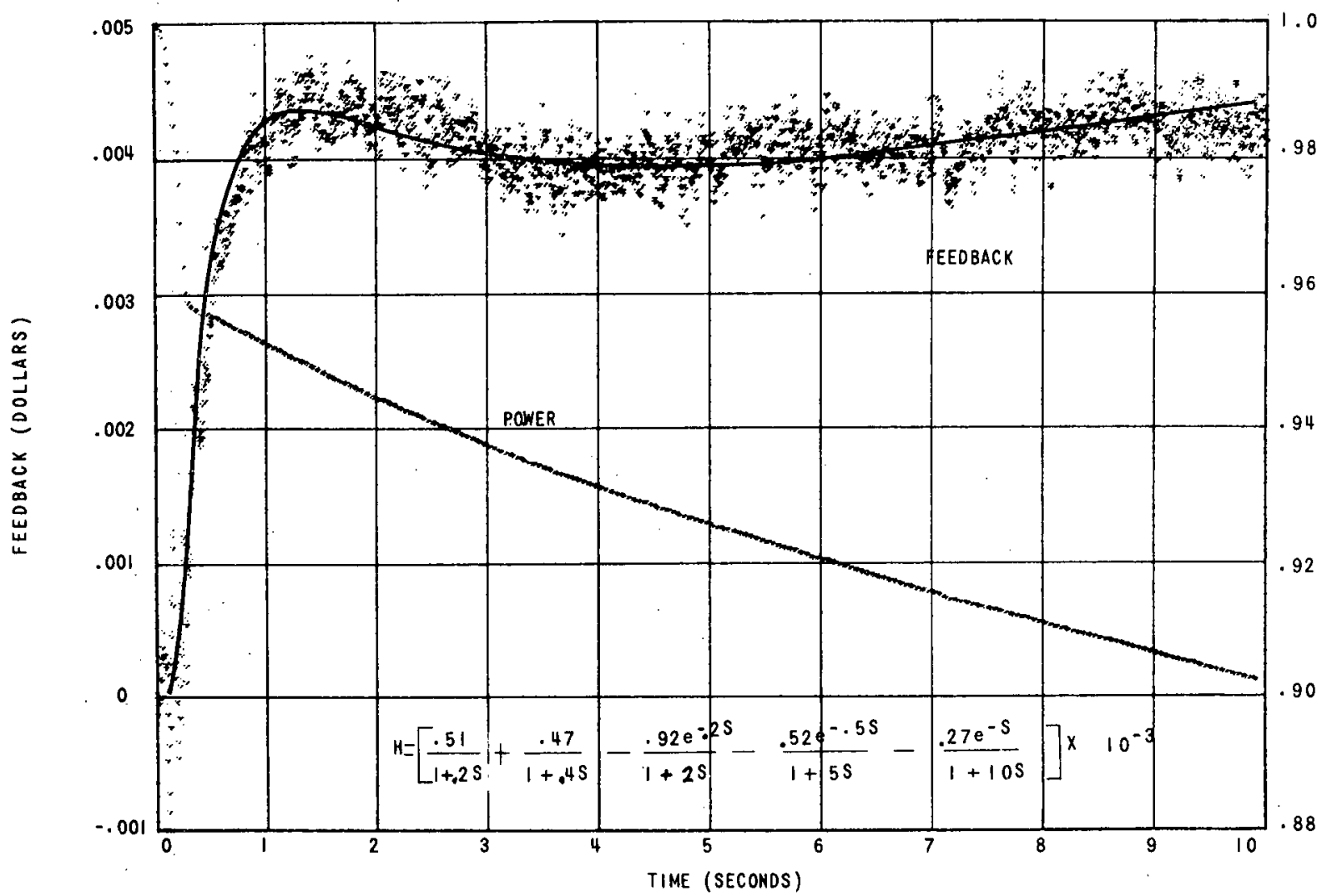

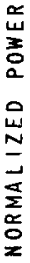

ID $-103-\mathrm{K} 5132$

Fig. 25. Corrected Feedback and Model for Run 26A at 25.0 MWt

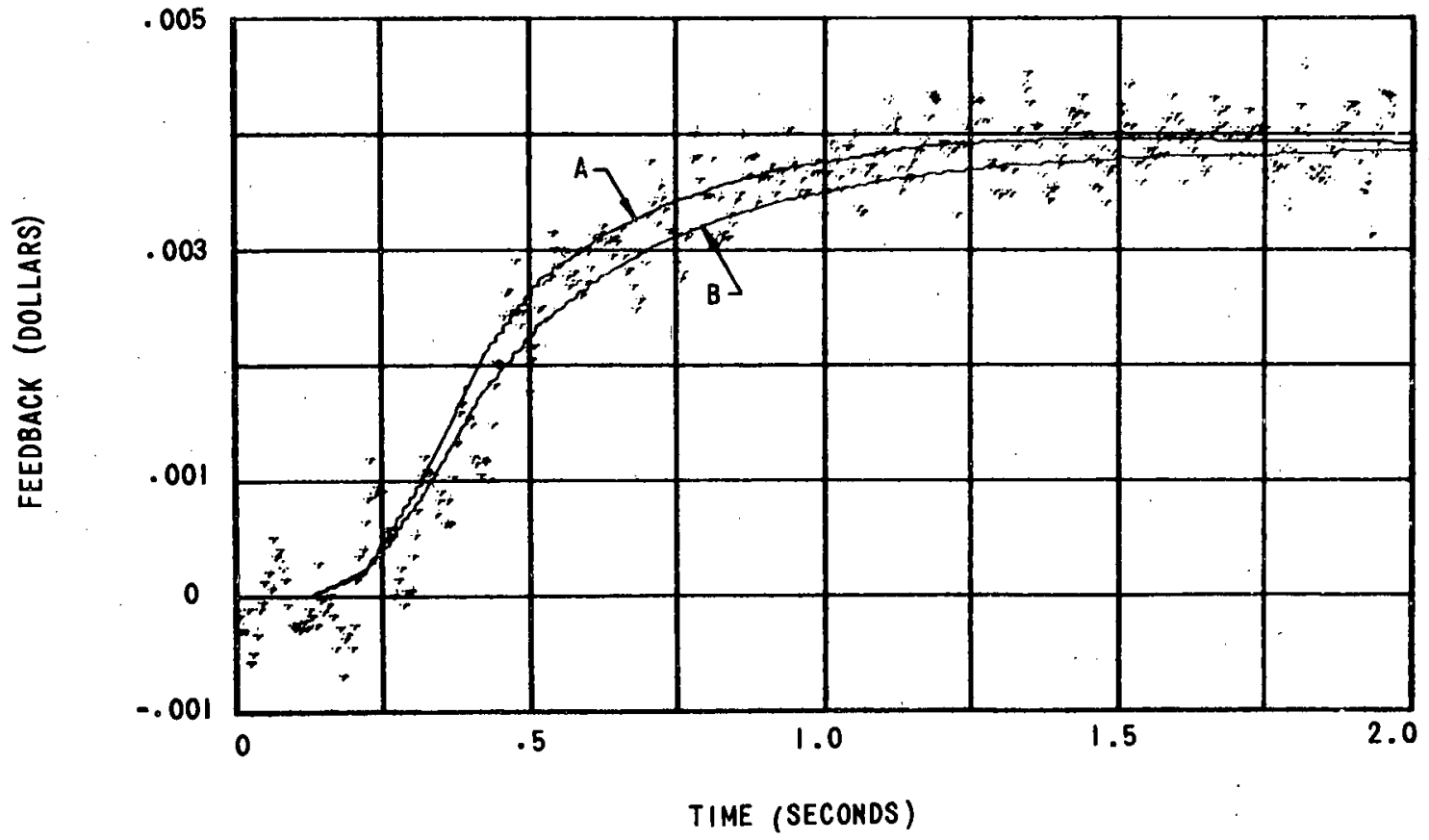

ID $-103-\mathrm{K} 5133$

Fig. 26. Corrected Feedback and Model for Run 26B at 22.5 MWt, Plotted on Expanded Scale 


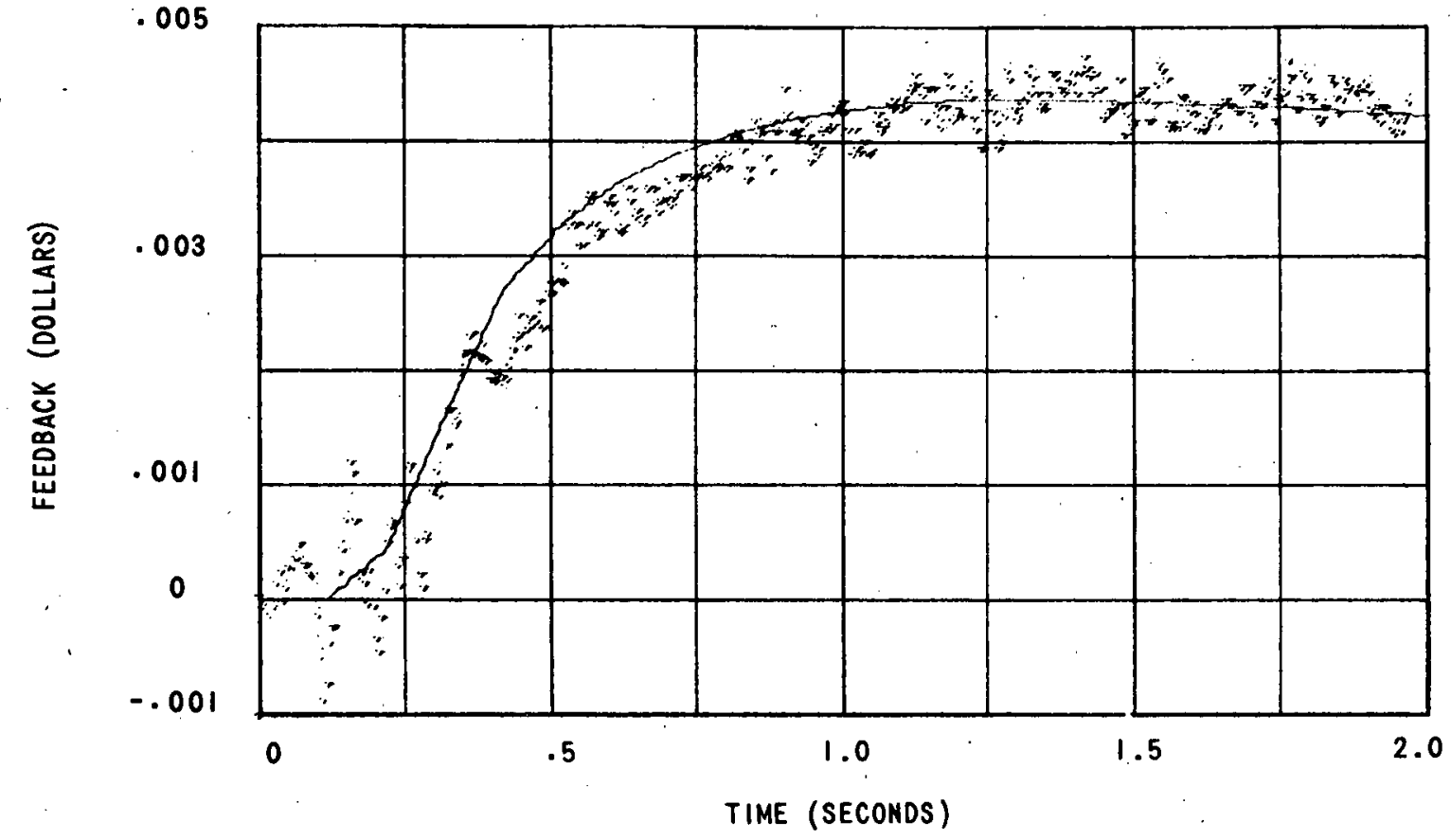

ID $-103-\mathrm{K} 5133$

Fig. 27. Corrected Feedback and Model for Run 26A at 25.0 MWt, Plotted on Expanded Scale

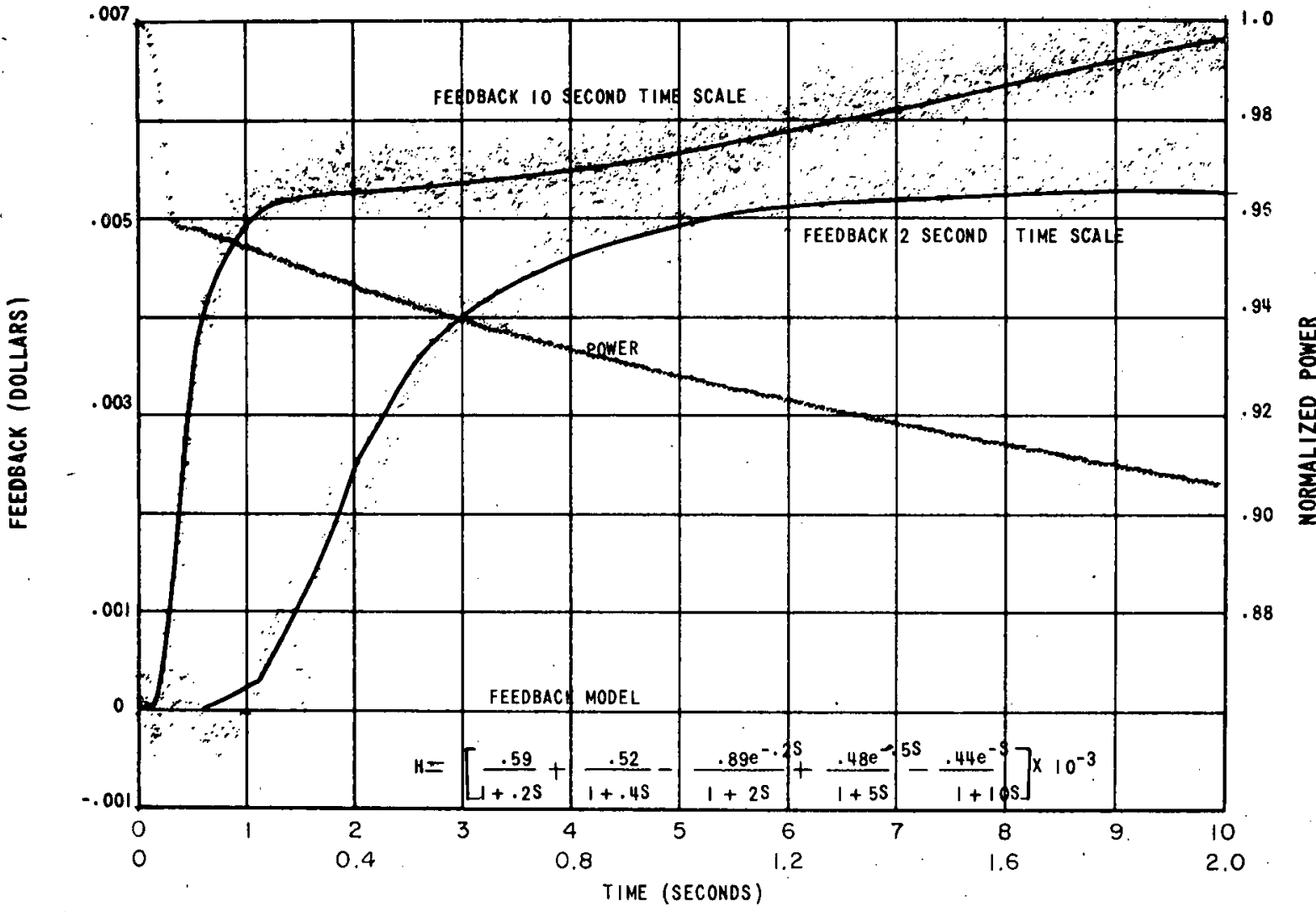

ID-103-K5134 Rev. 1

Fig. 28. Corrected Feedback and Model for Run 26B at 30:0 MWt 


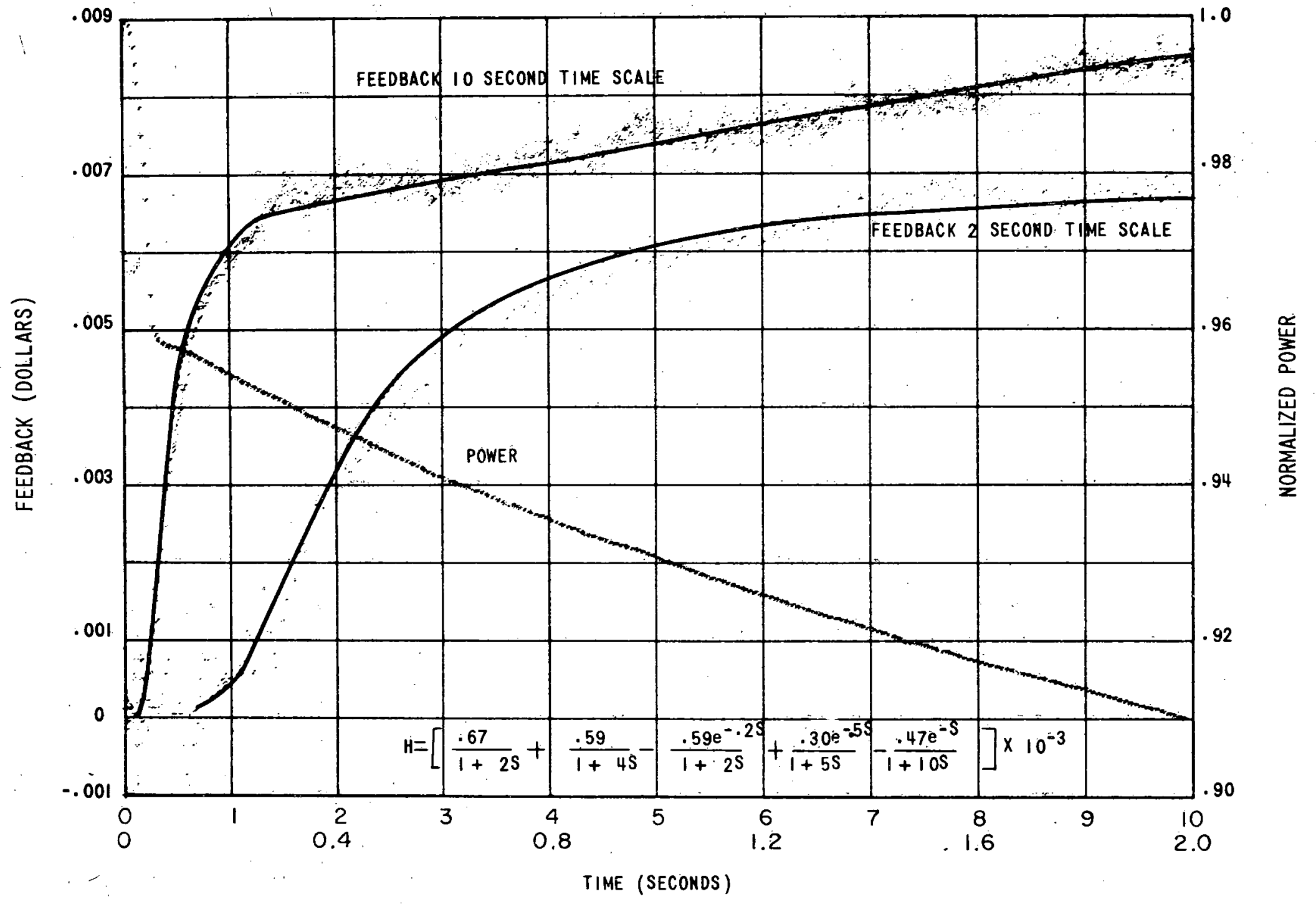

ID-103-K5135 Rev. 1

Fig. 29: Corrected Feedback and Model for Run 26A at 35:0 MWt 


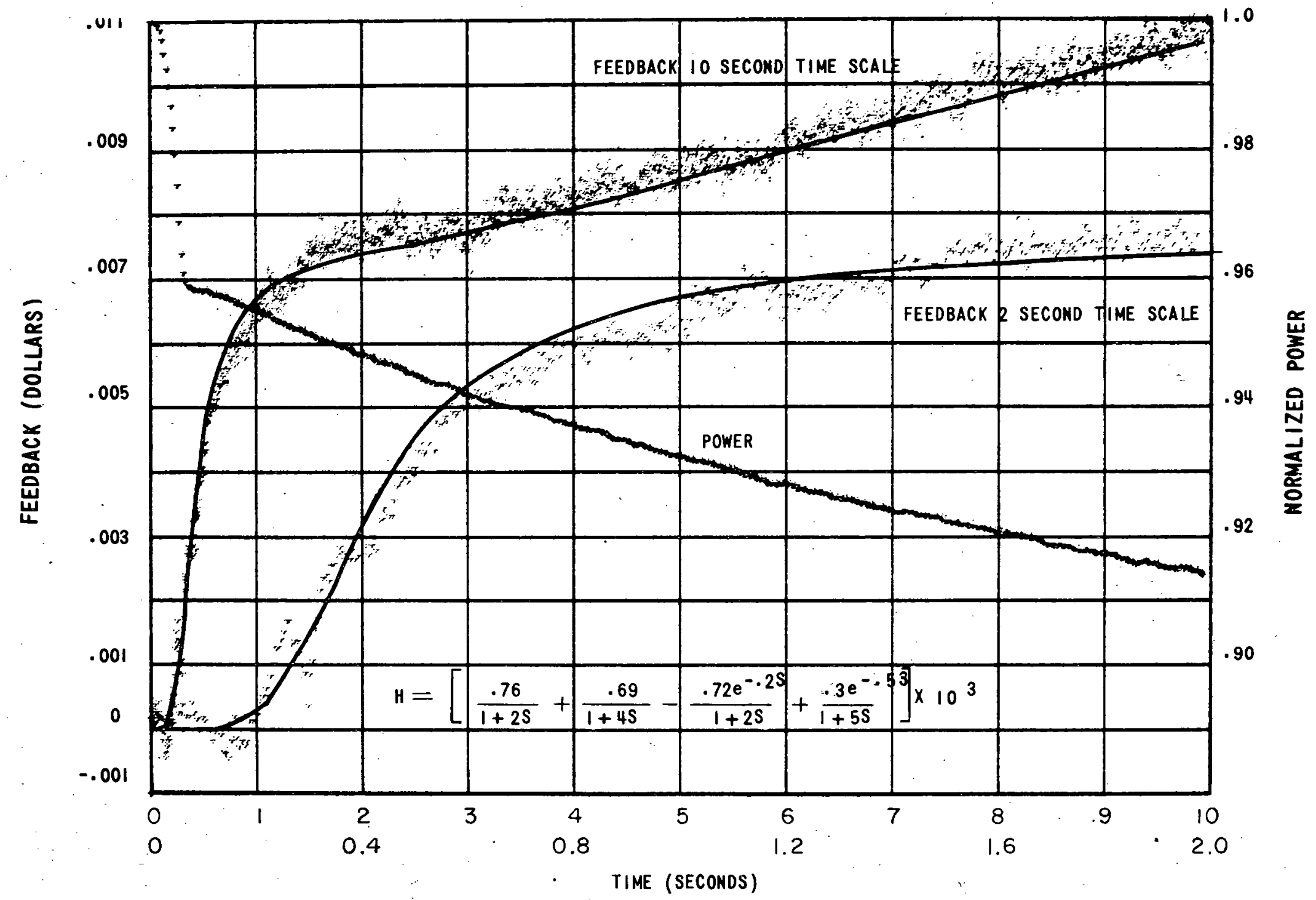

ID-103-K5136 Rev. 1

Fig. 30. Corrected Feedback and Model for Run 26B at $41.4 \mathrm{MWt}$ 


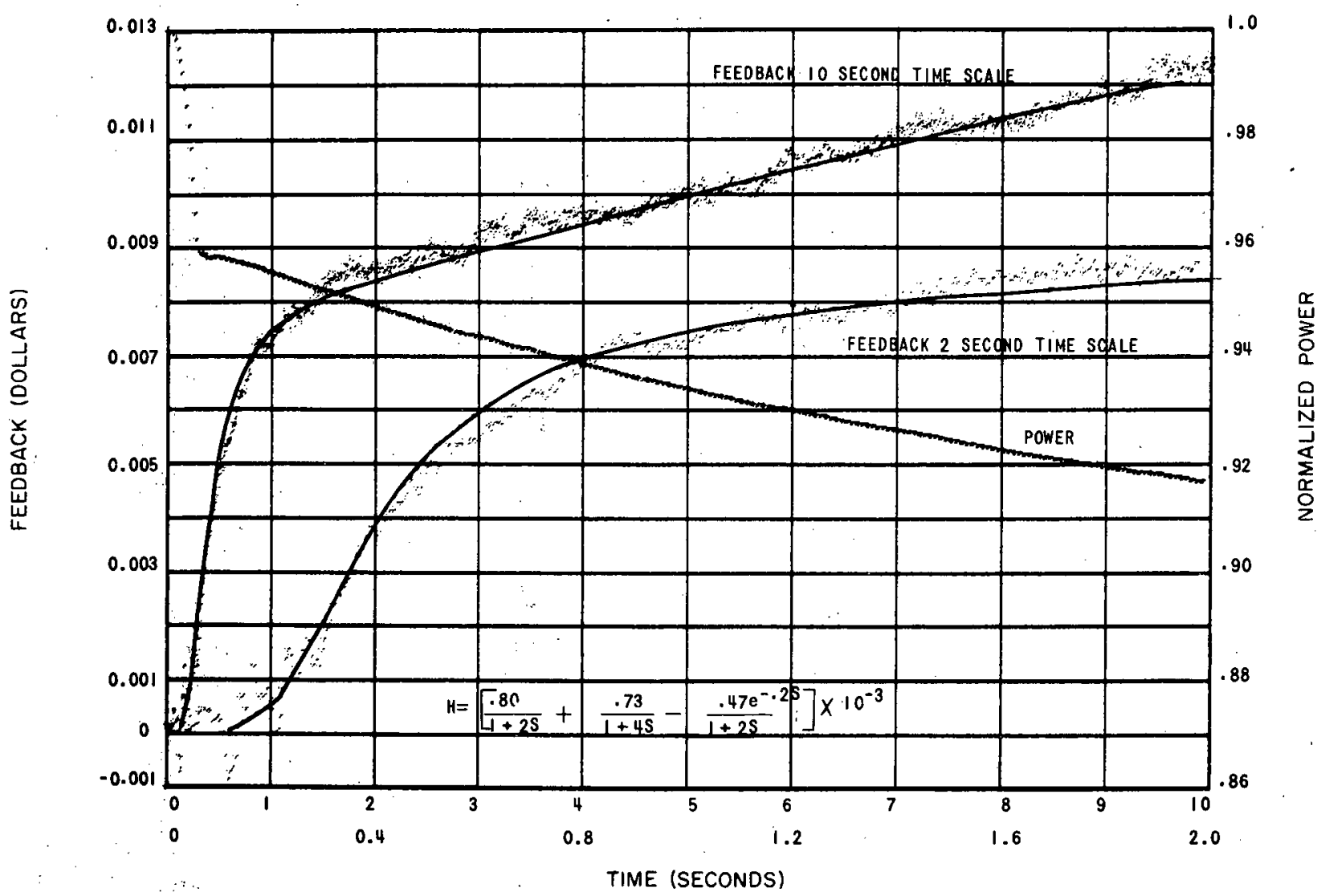

ID-103-K5137 Rev. 1

Fig. 31. Corrected Feedback and Model for Run 26A at 45.0 MWt

In choosing the parameters to fit the curves, we have imposed some restrictions. One is that the time constants were restricted to be the same for all power levels. Another was that the two prompt components were chosen approximately proportional to the power level. It is remarkable that the data can be fit this well with the rather severe restrictions. It gives considerable confidence in the procedures used.

One other restriction was considered but not rigidly enforced. The complete feedback function should approach the steady-state differential power coefficient as $s \rightarrow 0$. This was not required for two reasons. First, the steady-state differential power coefficient is not known to a high accuracy. Second, the rod-drop data extend only to $10 \mathrm{sec}$ and therefore should not be expected to give information on terms that have time constants greater than about $10 \mathrm{sec}$. One should not, therefore, consider the results to be inconsistent with the steady-state data. Another term with a long time constant can always be added to the feedback function. This will make very little change in the feedback over the first $10 \mathrm{sec}$ (and that small change can be compensated by small changes in the prompt terms), but would bring the function into agreement with the steady-state coefficient, whatever it might be. It would be misleading to include that term in our results as the time constant cannot be estimated from the $10 \mathrm{sec}$ of rod-drop data. 
The longest time constant used was $10 \mathrm{sec}$ and is not well defined by the data. The same results could have been obtained, for example, with a time constant of $15 \mathrm{sec}$, but with an amplitude of about $1 \frac{1}{2}$ times as large. The 0.2- and 0.4-sec time constants are also not accurately defined individually by the data. One could obtain nearly the same results by replacing these two by a single term with an intermediate time constant. The main justification for using the two terms is the heat-transfer analysis of Appendix A, which shows that the fuel and coolant time constants should cover the range from about 0.15 to $0.4 \mathrm{sec}$.

The data do not clearly define the transport lags. There would be little difference in the fit if these were simply incorporated in to the time constants. They were included only because we feel that physically there are some transport lags in the system and we used educated guesses for their magnitudes.

The above comments are to the effect that when one uses some 13 parameters to fit the data, there are a number of ways of choosing them and still obtaining essentially. the same result. The data determine only the important features of the feedback function. There must be coefficients having time constants in the 0.2 - to $0.4-\mathrm{sec}$ range to produce the sharp initial rise. There must be terms in the 2 -sec range to turn the feedback back down as observed in the 22.5- and 25-MW data, and produce the tendency to level out in the higher-power data. Then there must be terms in the $5-\mathrm{sec}$ range to turn the feedback back up again: Finally, some further delayed effects must be present to prevent the rise from being too great and to eventually produce the steady-state power coefficient. It would be unwise to consider that we have made an accurate determination of each individual component of the feedback function. However, we believe that the function as a whole is rather well established by these experiments.

Figure 24 contains two feedback-function models for $22.5 \mathrm{MW}$ : Model: $\mathrm{A}$ is the one adjusted to best fit the rod-drop data. Model $\mathrm{B}$ is a compromise chosen to give a fairly good fit to both rod-drop and oscillator data. This compromise is discussed further in Section V.C.

\section{Feedback Function by Compromise between Oscillator and Rod-drop Results}

There is fairly good agreement between the rod-drop and oscillator results on the prompt terms in the feedback function for all three power levels, 22.5, 30, and 41.4 MW. At 30 and 4l.4 MW, there is no important disagreement on any part of the feedback function, because at the se power levels the oscillator tests do not extend to low enough frequencies to give information on the delayed components. Only with the $22.5-\mathrm{MW}$ data is there some conflict, and this is only in the delayed components. The purpose of this section is to examine this $22.5-\mathrm{MW}$ conflict to see if one can 
arrive at possible corrections to the oscillator data which permit at least a reasonable compromise feedback function, giving approximate agreement with both oscillator and rod-drop results.

The disagreement is best illustrated in Fig. 32, where we have plotted the oscillator data and the feedback function, which gives a good fit to the rod-drop experiments. The rod-drop feedback function follows the data to about $0.1 \mathrm{~Hz}$, and then curls in toward the real axis near $0.2 \times 10^{-3}$ at low frequency. The oscillator data, on the other hand, continue roughly on a circle approaching zero along the imaginary axis at low frequency. We have fit the rod-drop data in a number of different ways, all of which have the same general behavior, and we are convinced that it is not possible to find a fit that will give significantly better agreement on the Nyquist plot.

We have also been unable to imagine sources of error in the roddrop data that could cause this discrepancy. Because the oscillator rod is known to rub at low frequency and not at high frequency, it is immediately under suspicion as a possible cause. We have therefore set up a model for the reactivity worth of the oscillator rod as a function of frequency, and show here that much of the discrepancy can be removed by making a correction based on this model.

The model assumes that a temperature gradient across the oscillator rod is produced by unequal heat-transfer rates into the oscillator-rod assembly from the surrounding fuel subassemblies. Call the time constant associated with this heat transfer $\tau_{\mathrm{b}}$ (bowing time constant). If the oscillator rod rotates at a frequency that is small compared to $l / \tau_{b}$, then it is expected to continually bow in one direction by about the amount it would bow under stationary conditions. If it rotates rapidly, then the temperature gradient cannot develop and the oscillator rod does not bow. We assume that the bowing changes the amplitude of the reactivity oscillation and that this amplitude can be expressed as a function of frequency and power by the approximation

$$
A(\omega, P)=A\left[1+\frac{\delta(P)}{1+i \omega \tau_{b}}\right],
$$

where $A$ is the unbowed amplitude, and $\delta(P)$ is the zero-frequency deviation expressed as a function of reactor power. Thus, $A(\infty, P)=A$ at high frequency, and $A(O, P)=A[1+\delta(P)]$ at low frequency.

If this frequency-dependent amplitude exists and is ignored, then the calculated feedback function will be in error by the amount

$$
\frac{\delta(P) / G_{0}(\omega)}{1+i \omega \tau_{b}}
$$

where $G_{0}(\omega)$ is the zero-power reactor transfer function. 


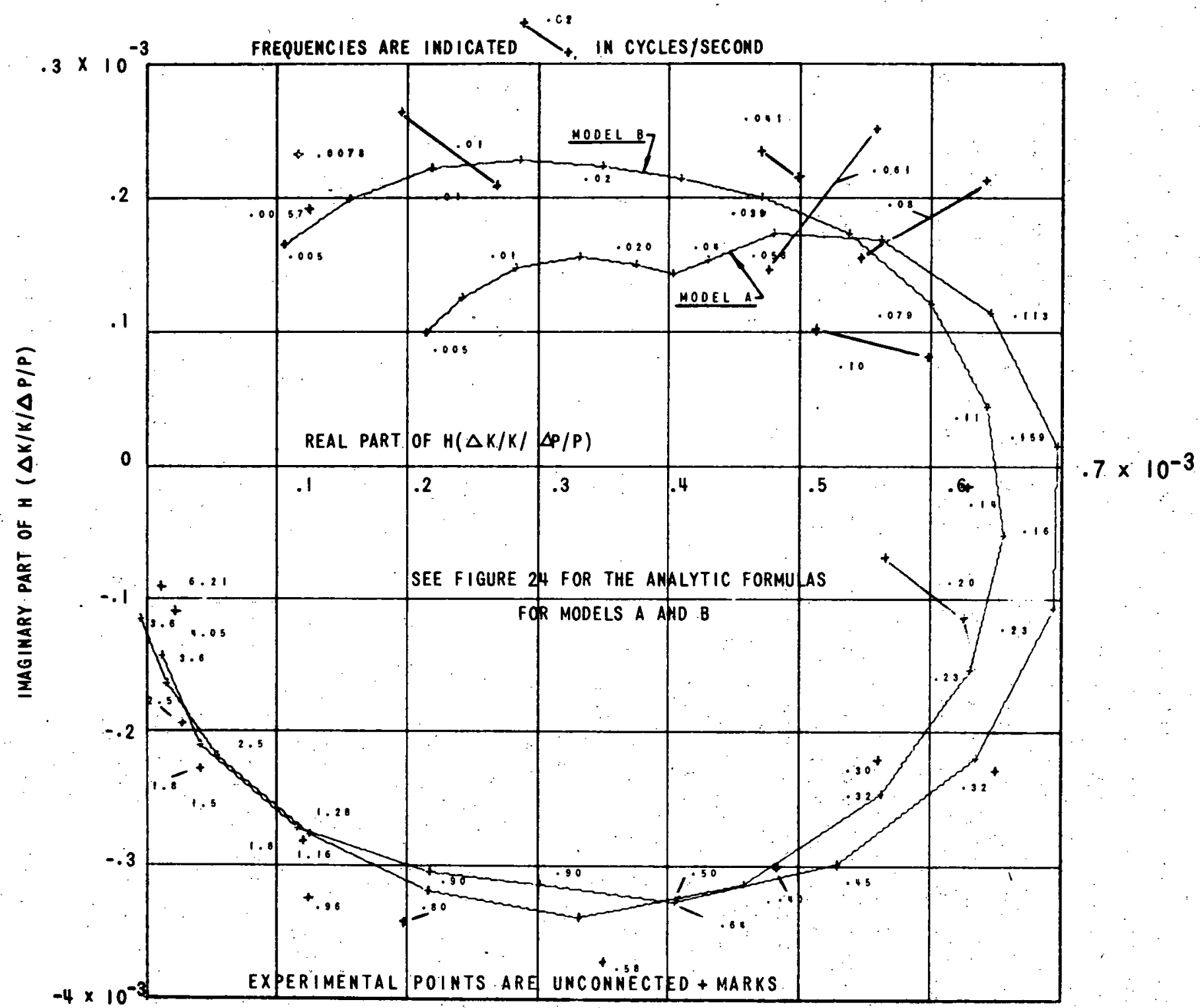

ID $-103-\mathrm{K} 5138$

Fig. 32. Nyquist Plot of Oscillator Feedback Function for Run 26B at 22.5 MWt, Corrected for Oscillator-rod Bowing 
We do not understand the heat-transfer and bowing effect in the oscillator assembly well enough to attempt a calculation of $\delta(P)$ and $\tau_{b}$ from the system design. We have to be content with simply trying values of these parameters to see if there are any reasonable values which would provide a correction to the oscillator feedback that would improve the agreement. This has been done: While we have not carefully optimized $\delta(P)$ and $\tau_{b}$ to maximum agreement, we find that one cannot do very much better than to take

$$
\delta(22.5 \mathrm{MW})=0.05
$$

and

$$
\tau_{\mathrm{b}}=5 \mathrm{sec} \text {. }
$$

In Fig. 32, we have plotted the corrected feedback data. As desired, the low-frequency points are moved back away from the imaginary axis. The solid curve indicated as Model $B$ is our best compromise fit between this corrected data and the rod-drop data. The feedback versus time for this model in the rod drop is plotted as Model B in Fig. 24. Figure 32 also shows the Nyquist plot for Model $A$, the model that best fits the rod-drop data.

Model B gives a fairly good fit to both sets of data. There are the two points at $0.02 \mathrm{~Hz}$ which deviate significantly from the models. The compromise model does not extend to quite large enough positive and negative values. But except for the $0.02-\mathrm{Hz}$ points, the agreement is probably within experimental accuracy. In the time domain, the compromise model does not contain the sag seen in the data in the 3-to 5-sec range with a later rise after $5 \mathrm{sec}$. This is considered a significant disagreement as it seems to occur in nearly all rod-drop tests. When a model contains the sag in the time domain, it also prevents the Nyquist plot from achieving sufficiently large positive imaginary values as in Model $A$ of Fig. 32 .

Thus, although the compromise model does fit the corrected data fairly well, it is subject to some deficiencies and leaves the impression that some errors are still not accounted for in either or both the rod-drop and oscillator results. The oscillator bowing is possibly more complicated than the simple model assumed here.

D. Further Discussion and Summary

It is difficult to say which of the three approaches presented above leads to the best estimate of the feedback function. The oscillator tests give a set of data that are fairly consistent with each other, but only the 22.5-MW data extend to low frequency and give information on delayed 
components. The known bowing of the oscillator rod leaves one doubtful that the low-frequency data can be trusted.

The rod-drop data, after an assumed correction in rod worth is made, result in a set of feedback functions that appear consistent with one another in.view of our physical model of bowing effects. The prompt components scale with power level, while the delayed (mainly bowing) effects tend to saturate and disappear as the core gets tighter at high power. It also seems significant that the two sets of data, namely, the 25-, 35-, and 45-MW data on the one hand, and the 22.5-,30-, and 41.4-MW data taken at a later date, are consistent with one another. The only weak points and questions are associated with the fairly arbitrary correction for change in rod worth and the fact that the data extend only to $10 \mathrm{sec}$, which makes it impossible to see feedback components with long time constants.

The compromise approach has the advantage of giving some weight to all the available data. But the resulting feedback function still has some features that seem to be effectively contradicted by the rod-drop experiments.

Our opinion is that if one is forced to choose, the balance.swings in favor of the models predicted mainly from the rod-drop experiments plotted in Figs. 24-31.

These models contain basically five terms (the fifth has disappeared at 41.4 and $45 \mathrm{MW}$ ). The first two are to be interpreted as mainly due to fuel and coolant expansion. The third and fifth are presumed to be mainly due to compression of the core caused by bowing of the outer core elements and stainless steel blanket. The fourth term is a negative reactivity coefficient and could be partly due to the rod-bank effect. At the lower power levels, however, this effect is too strong to be explained entirely by rod-bank effects and must be partly also a bowing effect. Under some conditions of partial restraint, there can be bowing effects which tend to expand the core.

The interpretation of the first two terms as fuel and coolant expansion and the third term as bowing in Row 7 is strengthened by the heattransfer analysis of Appendix $A$, which shows that the time constants are of the right magnitude. The time constants for bowing in Row 8 range from 5 to $10 \mathrm{sec}$ with transport lags of 0 to $7 \mathrm{sec}$. We cannot say that this corresponds closely to our fifth term, which was chosen to have a time constant of $10 \mathrm{sec}$ and a time lag of $1 \mathrm{sec}$. However, the Row 8 bowing during the $10 \mathrm{sec}$ of the experiment can probably be approximated by a combination of our fifth term with part of the fourth term.

We did not find a heat-transfer process that would be likely to yield a negative power coefficient of reactivity with a 5-sec time constant. Calculations of heat transfer to the control-rod drive shafts by Persiani and 
DeShong' seem to indicate no components with 5 -sec time constants. But the heat-transfer process in the control rods is complicated and so should not be completely ruled out as a source of the 5 -sec term.

One might also compare the magnitudes of the feedback terms with the results of theoretical studies. ${ }^{2-4}$ The studies, however, have not generally included estimates of the bowing effects. It is then only possible to make comparisons with the two prompt terms due mainly to fuel and coolant expansion. The theoretical calculations for these effects give somewhat smaller amplitudes than the experimental results. The difference may be due to prompt bowing and subassembly radial expansion. The theoretical calculations indicate a strong radial-expansion coefficient if the core is tight or none if it is loose. The real situation is undoubtedly intermediate, and taking this into account, one can say that there is then no disagreement between the experiment and the calculations.

\section{RECOMMENDATIONS FOR FUTTURE EXPERIMENTS}

We believe that the Run 26 experiments have proved that rod-drop experiments are basically capable of yielding information to good accuracy on the transient feedback function. The only question on the results from the present experiments has been the fairly arbitrary correction to the worth of the rod because of an assumed change in worth with power level. If one can devise a technique for accurate calibration of the rod at power, this question would be eliminated.

The rod could be calibrated at power with acceptable accuracy if only the rod could be moved out faster than the present 0.28 -sec drop time. A suitable goal to aim for would be a drop time of $0.1 \mathrm{sec}$. Our feedback analysis suggests that with the present 0.28 -sec drop time, about $20 \%$ of the feedback during the first second comes while the rod is moving. In a $0.1-$ sec drop, this $20 \%$ could be reduced to $7 \%$, which would be acceptable. One could make this small correction in the analysis with good confidence. The experimental procedure would be to drop the rod and record power and position. The reactivity versus time would be calculated by inverse kinetics. The feedback versus time would then be obtained by subtracting the reactivity at the time the rod is out $(0.1 \mathrm{sec}$ in this case) from the net reactivity curve. One would fit this with a feedback function and correct the data for the feedback occurring while the rod was in motion. It would be unnecessary to do the low-power calibration presently required.

The same technique could be used with the existing stainless steel rod. In fact, our procedure of adjusting the rod calibration to accommodate the predicted feedback function is nearly equivalent to the suggested procedure. However, one would have a great deal more confidence if the necessary correction could be reduced by a factor of three. 
There are a number of ways of obtaining a faster reactivity change. One is to use a standard control rod and move it through only 3 or 4 in. instead of the present 14 -in. stroke. It would also be necessary to increase the driving pressure by a factor of about two and provide a new dashpot design. This would have the advantage that one could use a standard control rod and remove the stainless steel rod.

If the design problems are too difficult to accomplish the above procedure, one could consider alternatives. It might be easier to achieve the fast reactivity change with a lighter rod, perhaps a ${ }^{10} \mathrm{~B}$ rod. This would have the disadvantage of requiring the displacement of a standard control rod and would depress the reactivity of the reactor. Also, if one were forced to use only negative reactivity transients, the rod would have to be moved into the core rather than being dropped out. There are, of course, other possibilities such as liquid or gaseous control elements. All seem to have some design difficulties, and we suspect that the first suggestion of a small fast movement of a standard control rod is the easiest to accomplish.

It is even reasonable to consider the possibility of determining the feedback function completely by rod-drop tests and eliminating the oscillator tests. Rod drops can be done more quickly and permit one to dispense with the oscillator rod and replace it with a fuel subassembly or a standard control rod. Inherently, one expects to obtain higher accuracy from oscillator tests. This is not true of the present oscillator, and only time will tell whether we can obtain one that will do the job. We recommend that efforts be continued to develop a good oscillator rod.

We also recommend that consideration be given to developing an autorod system for EBR-II, i.e., a rod and control system that can be programmed to maintain constant power level. Such a system would be useful in rod-drop tests to obtain the long-time-constant components of the feedback function. The problem with rod drops is that if one wished to follow a test for more than perhaps $30 \mathrm{sec}$, the power changes by a large amount from its original value. Since the magnitudes of the delayed components of the feedback function depend upon power, the problem of interpreting the experimental results is greatly aggravated by these large changes. It is difficult, if not impossible, to distinguish between feedback coming from long-time-constant terms and feedback due to the power dependence of the more prompt terms. With an autorod, the power could be permitted to drop $10 \%$ and then be held constant, thus defining the feedback function at a particular power level rather than averaged over a wide range. There must be a technique for accurate calibration of the autorod if it is to be useful.

Another problem with long-time rod drops (or very-low-frequency oscillator tests) is that the primary-tank temperature eventually begins to change. Automatic control of the secondary system would be desirable so as to maintain constant temperature in the primary tank. 


\section{APPENDIX A \\ Heat-transfer Calculations}

The feedback analysis indicates that the feedback during the first 10 sec can be broken down into about five components: two promptnegative-coefficient terms with time constants in the 0.2 - to $0.4-\mathrm{sec}$ range, two delayed-positive-coefficient terms with 2 - and 10-sec time constants, and a 5-sec negative-coefficient term. These were obtained from analysis of the experimental data with little regard to whether the terms had any physical significance. We regard this work mainly as a determination of the power coefficient and not an explanation of its origin.

However, we have also done a few heat-transfer calculations to see if the time constants obtained experimentally might correspond to particular heat-transfer processes. We have been gratified to find that of our five terms, three have about the right time constant to correspond to the physical process envisioned. The 0.2 - and $0.4-\mathrm{sec}$ terms are due mainly to fuel and coolant expansion, and the $2-\mathrm{sec}$ term is due to bowing in Row 7 .

The heat-transfer calculations have been done with the ARGUS code. We present the results here without a description or discussion of the model, which was admittedly a crude one. The calculations were of the temperature response to a step input of power. The effective time constant is then the time to reach $63 \%$ of the equilibrium value. Figures 33,34 , and 35 give the temperatures versus time at three axial positions in Rows 1,4 , and 6 , respectively. The temperatures are given for the coolant, fuel centerline, and fuel-cladding interface. Close examination indicates that the temperature increases can all be well approximated by an expression of the form

$$
\Delta \mathrm{T}(\mathrm{t})=\Delta \mathrm{T}_{\mathrm{f}}\left(1-\mathrm{e}^{-\mathrm{t} / \mathrm{T}}\right)
$$

with $\tau$ chosen differently for each location but always in the range 0.15$0.4 \mathrm{sec}$. One thus expects the prompt feedback due to fuel and coolant to involve a continuum of time constants over that range. One would hardly be able to distinguish between that continuum and our choice of one term at $0.2 \mathrm{sec}$ and one at $0.4 \mathrm{sec}$ in fitting the rod-drop data.

To estimate the time constant for bowing of the subassembly cans in Rows 7 and 8 , we have set up a calculation of heat transfer from Row 6 into Row 7 and from Row 9 into Row 8. The appropriate time constants are those for the inner can wall of Row 7 and the outer can wall of Row 8 . The results for Row 7 are given in Fig. 36, and for Row 8 in Fig. 37. The temperatures of the can versus time are given at five axial locations. The most important location for bowing effects is believed to be near the top of the core, because much below that location the $\Delta \mathrm{T}$ is small, and much above that location the lever arm for the bowing action is small. From 


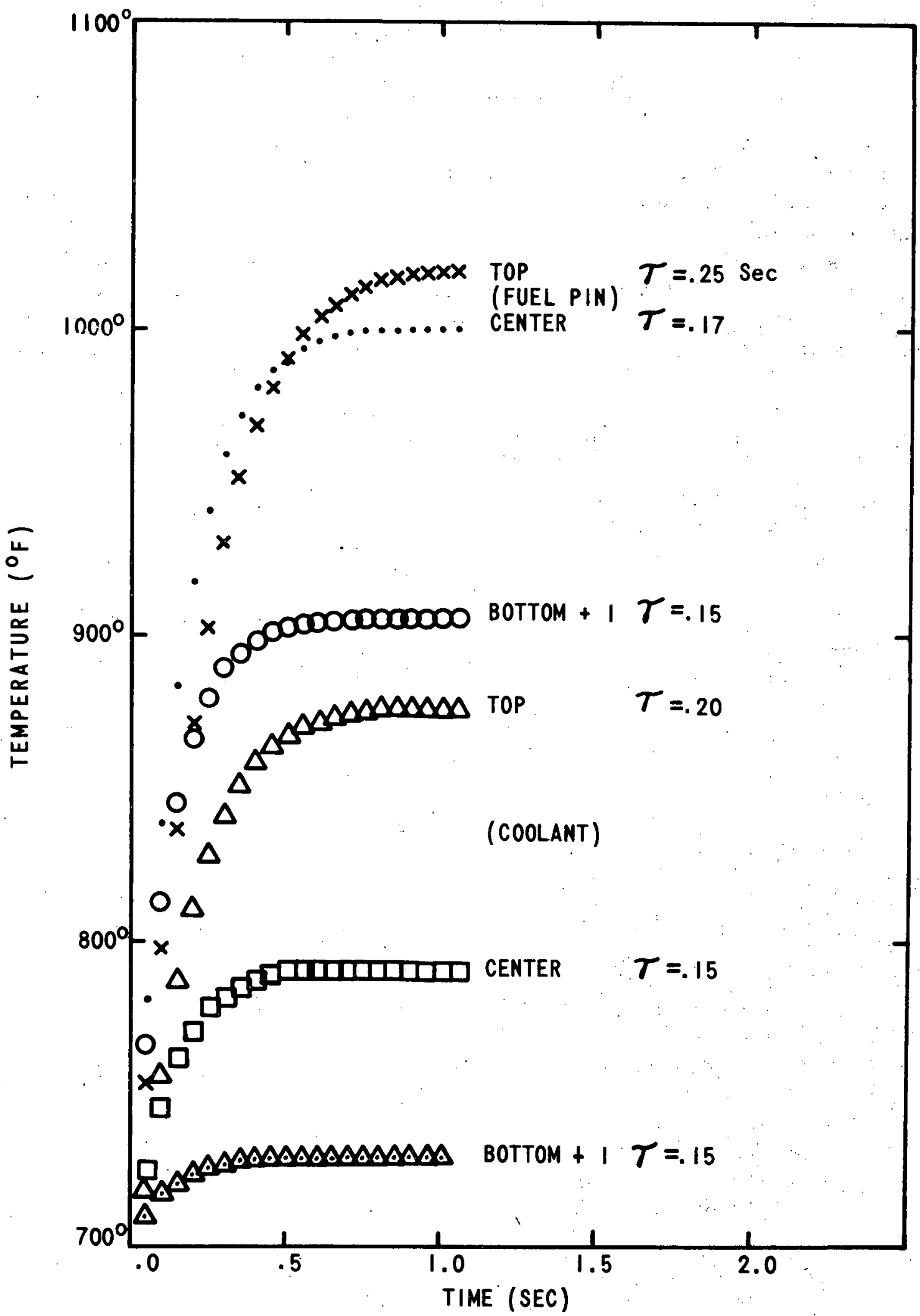

ID -103-K5139 Rev. 1

Fig. 33. ARGUS-calculated Temperatures for Row 1 


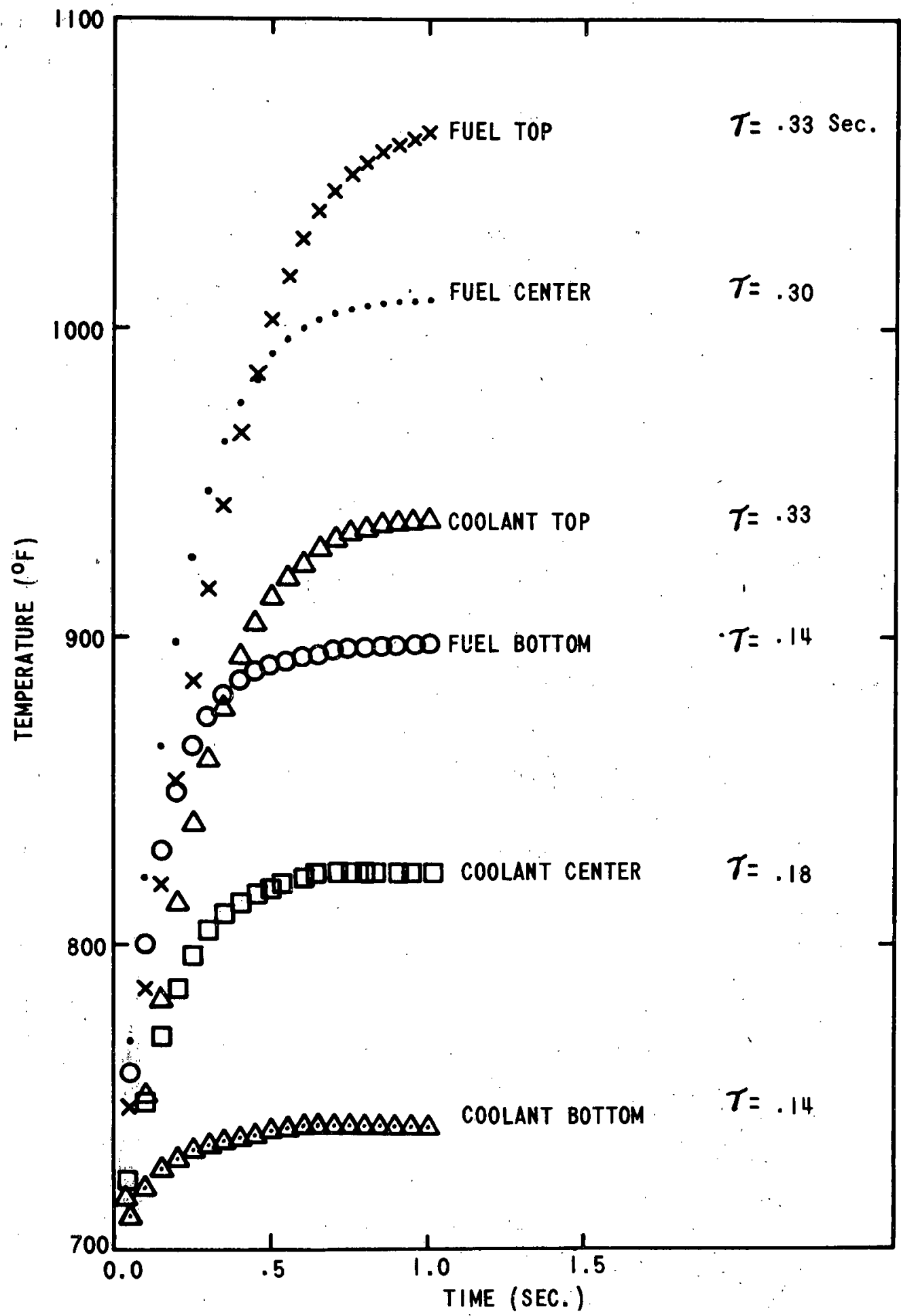

ID-103-K5140 Rev. 1

Fig. 34. ARGUS-calculated Temperatures for Row 4 


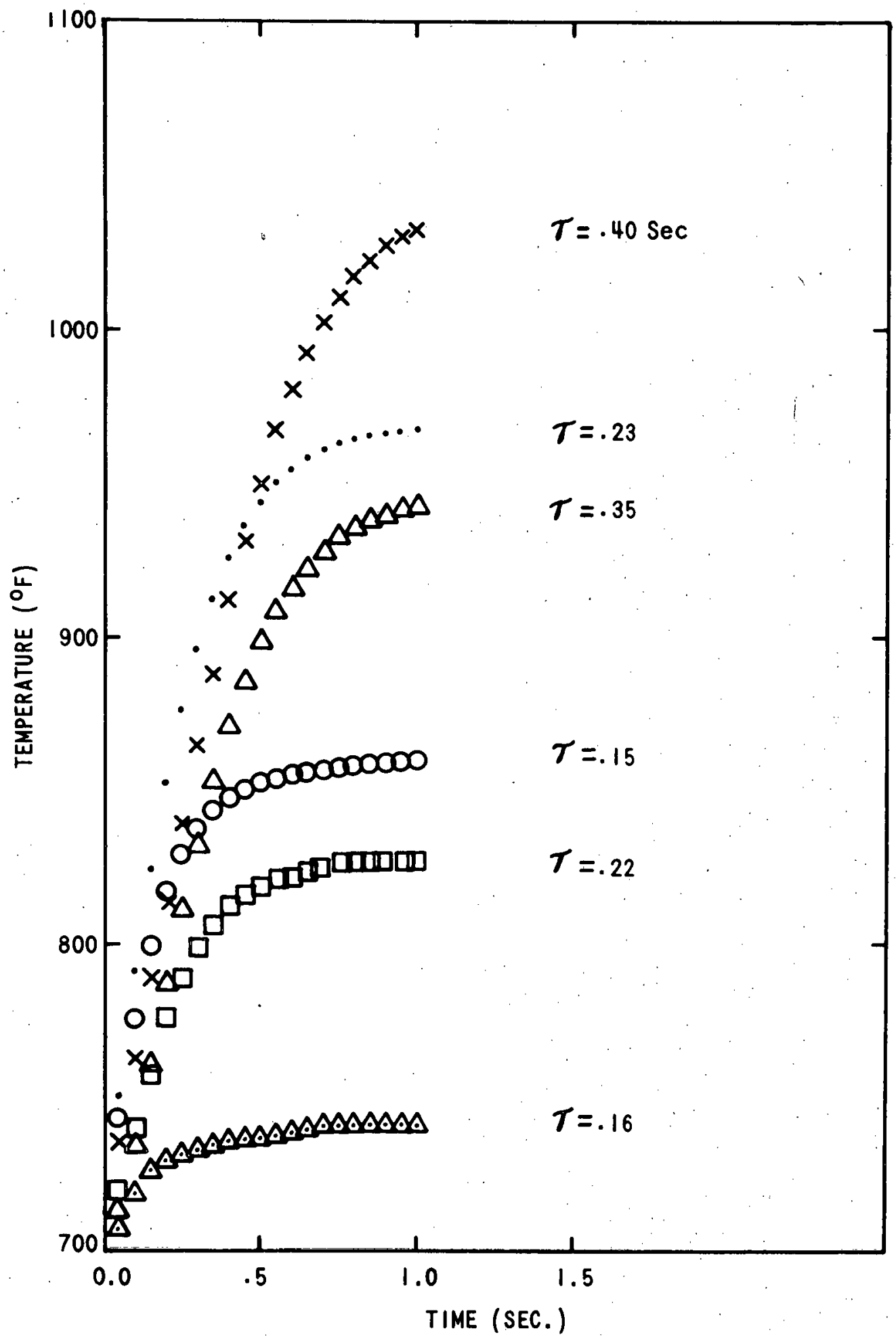

ID -103-K5141 Rev. 1

Fig. 35. ARGUS-calculated Temperatures for Row 6 


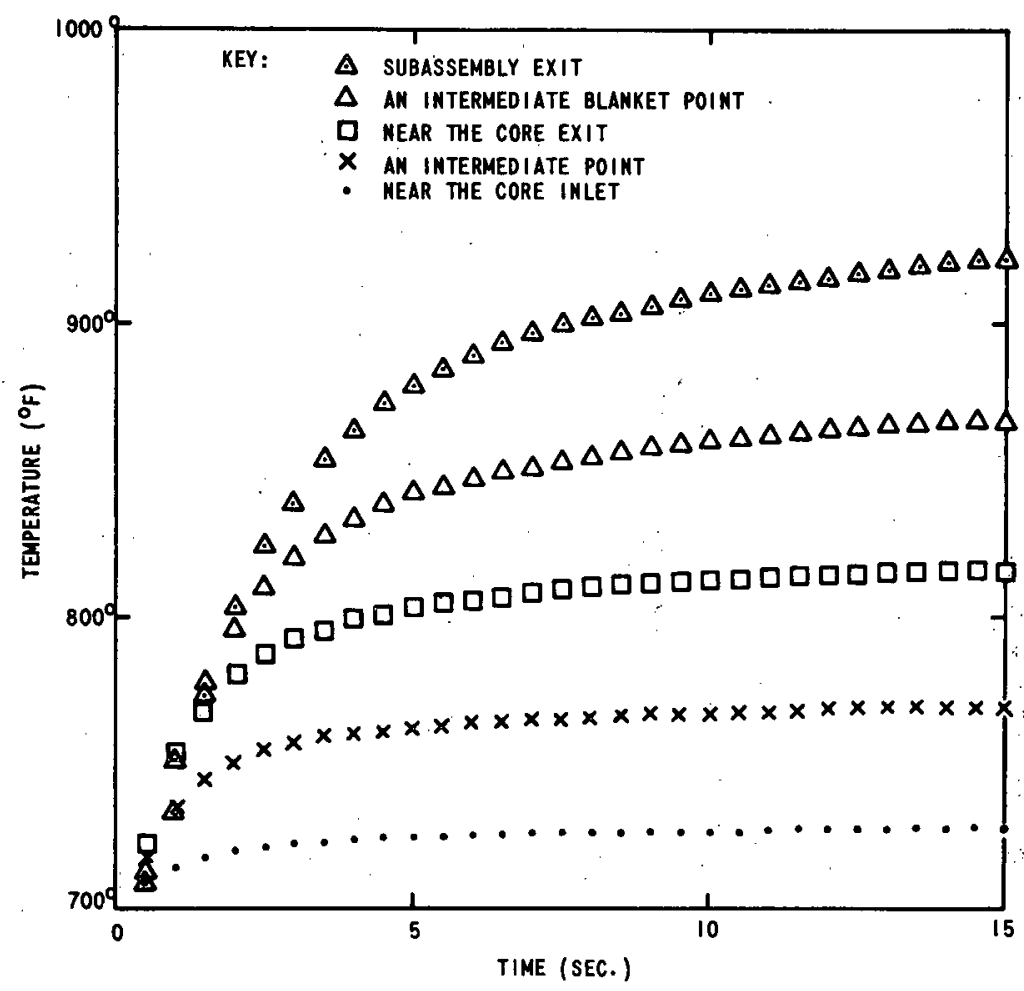

Fig. 36

ARGUS-calculated Temperatures for Row 6-7 Interface

ID-103-K5142

Fig. 37

ARGUS -calculated Temperatures for Row 8 -9 Interface

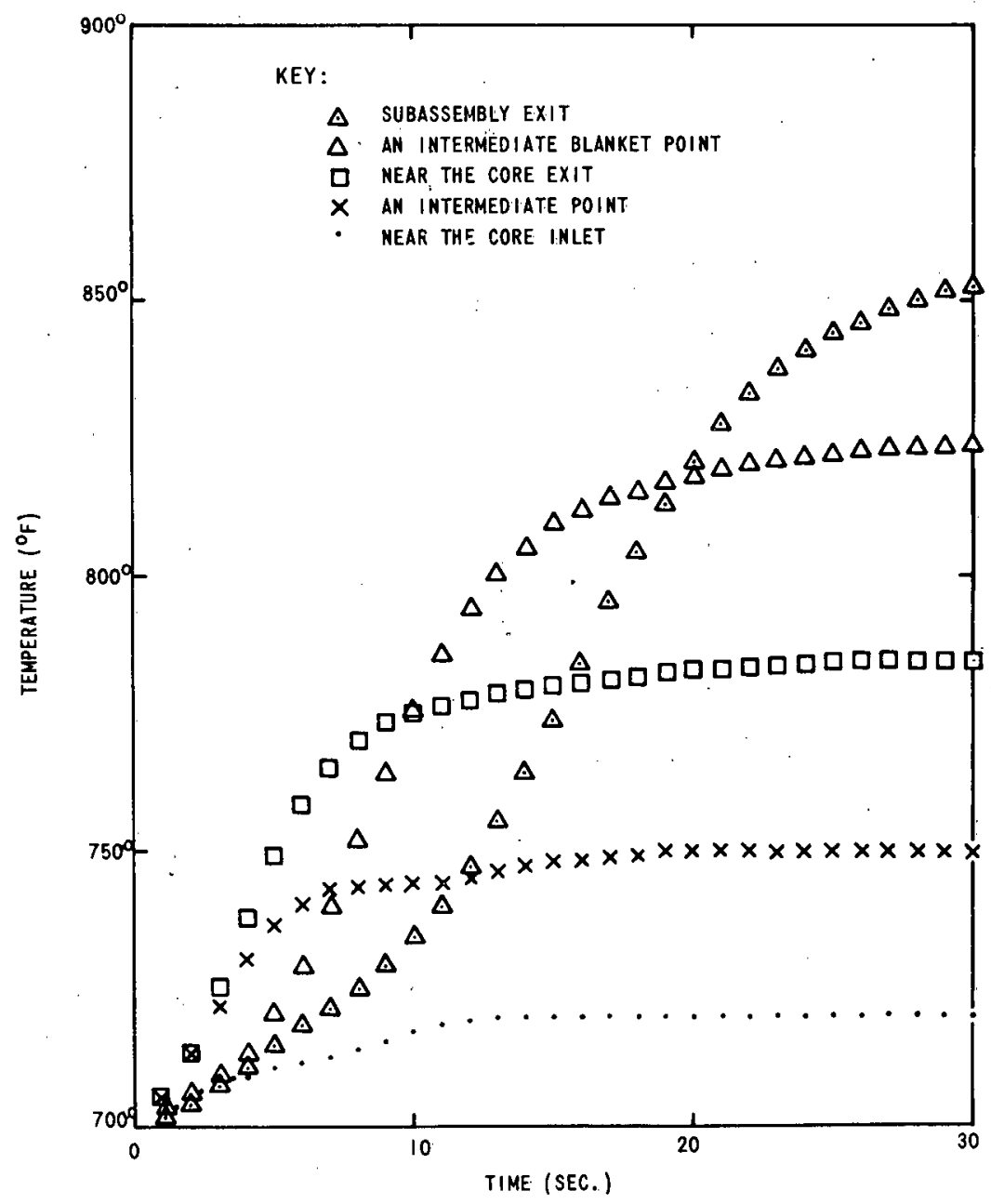


this point of view, our use of a 2 -sec time constant and 0.2 -sec delay time fits in fairly well as a suitable average for the Row 7 bowing. The 0.2 -sec delay may be a trifle long, but that is of little consequence.

The situation is not quite as good for Row 8 . There the effective time constants appear to range from 5 to $10 \mathrm{sec}$ with time delays of 0 to perhaps $7 \mathrm{sec}$. Our last positive coefficient presumably associated with Row 8 bowing had a time constant of $10 \mathrm{sec}$ and a time delay of $1 \mathrm{sec}$. This should not, however, be regarded as a real disagreement, because the $10 \mathrm{sec}$ of rod-drop data do not accurately determine the parameters of this last term. The continuum of time constants and time delays associated with Row 8 may produce about the same feedback as that contributed by our fifth feedback term combined with part of the fourth term.

We have not found a heat-transfer process that seems likely to explain the negative power coefficient of reactivity associated with our fourth term, which has a time constant of $5 \mathrm{sec}$. We could speculate that this term is mainly due to the rod-bank effect, except that it seems to saturate and disappear at $45 \mathrm{MW}$; in addition, the analysis of heat transfer to the controlrod drive shafts by Persiani and DeShong ${ }^{1}$ does not suggest a time constant near 5 sec. In some parts of the reflector or blanket, bowing may give rise to negative-power-coefficient effects having a time constant near 5 sec. 


\section{APPENDIX B \\ Delayed-neutron Constants}

The following effective delayed-neutron fractions and decay constants have been used in the inverse kinetics and transfer-function calculations.

\begin{tabular}{c} 
Group \\
\hline 1 \\
2 \\
3 \\
4 \\
5 \\
6
\end{tabular}

$$
\frac{\beta_{i}}{0.000258}
$$$$
\tau_{\mathfrak{i}}(\sec )
$$$$
0.0127
$$$$
0.0317
$$$$
0.115
$$$$
0.311
$$$$
1.40
$$$$
3.78
$$ 


\section{ACKNOWLEDGMENTS}

We acknowledge the valuable assistance of I. A. Engen, G. L. Grasseschi, M. R. Tuck, and R. A. Call, who handled much of the data processing for this work:

\section{REFERENCES}

1. P. J. Persiani and J. A. DeShong, "EBR-II Control-rod-bank Dynamics," Reactor Development Program Progress Report, February 1968, ANL-7427, p. 46.

2. H. H. Hummel and L. J. Bryant, "Stability of EBR-II," Proceedings of Physics of Fast and Intermediate Reactors, IAEA, Vienna, p. 107 (1962).

3. L. J. Koch, W. B. Loewenstein, and H. O. Monson, Addendum to Hazard Summary Report, Experimental Breeder Reactor-II (EBR-II), ANL-5719 Addendum, p. 85 (June 1962).

4. P. E. Blomberg, personal communications. 